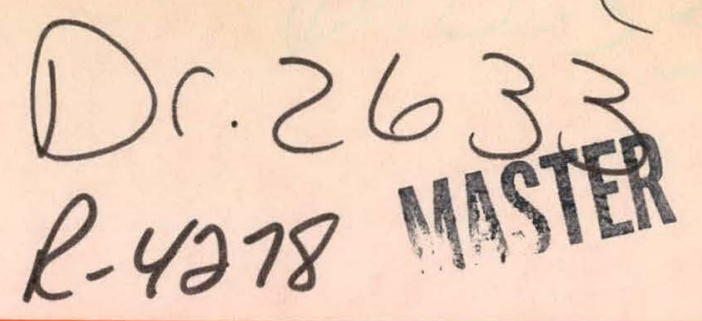

\title{
A Simplified Clear Sky Model for Direct and Diffuse Insolation on Horizontal Surfaces
}

Richard E. Bird

Roland L. Hulstrom
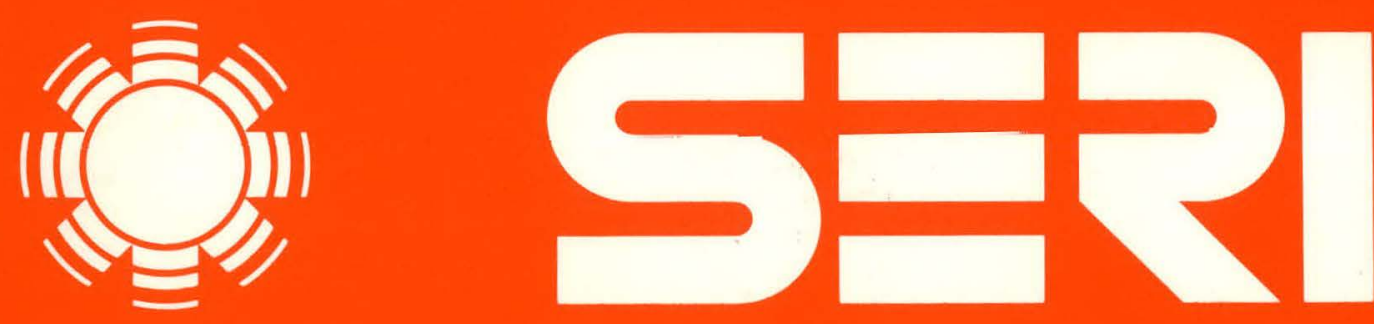

Solar Energy Research Institute A Division of Midwest Research Institute

1617 Cole Boulevard

Golden, Colorado 80401

Operated for the

U.S. Department of Energy under Contract No. EG-77-C-01-4042 


\section{DISCLAIMER}

This report was prepared as an account of work sponsored by an agency of the United States Government. Neither the United States Government nor any agency Thereof, nor any of their employees, makes any warranty, express or implied, or assumes any legal liability or responsibility for the accuracy, completeness, or usefulness of any information, apparatus, product, or process disclosed, or represents that its use would not infringe privately owned rights. Reference herein to any specific commercial product, process, or service by trade name, trademark, manufacturer, or otherwise does not necessarily constitute or imply its endorsement, recommendation, or favoring by the United States Government or any agency thereof. The views and opinions of authors expressed herein do not necessarily state or reflect those of the United States Government or any agency thereof. 


\section{DISCLAIMER}

Portions of this document may be illegible in electronic image products. Images are produced from the best available original document. 
Printed in the United States of America Available from:

National Technical Information Service

U.S. Department of Commerce

5285 Port Royal Road

Springfield, VA 22161

Price:

Microfiche $\$ 3.00$

Printed Copy $\$ 5.25$

\section{NOTICE}

This report was prepared as an account of work sponsored by the United States Government. Neither the United States nor the United States Department of Energy, nor any of their employees, nor any of their contractors, subcontractors, or their employees, makes any warranty, express or implied, or assumes any legal liability or responsibility for the accuracy, completeness or usefulness of any information, apparatus, product or process disclosed, or represents that its use would not infringe privately owned rights. 


\section{SERI/TR-642-761 \\ UC CATEGORIES: UC-59;61,62,63}

\section{A SIMPLIFIED CLEAR SKY MODEL FOR DIRECT AND. DIFFUSE. INSOLATION ON HORIZONTAL SURFACES}

RICHARD E. BIRD

ROLAND L. HULSTROM

FEBRUARY 1981

PREPARED UNDER. TASK NO. 1093.00

\section{Solar Energy Research Institute}

A Division of Midwest Research Institute

1617 Cole Boulevard

Golden, Colorado 80401

Prepared for the

U.S. Department of Energy

Contract No. EG-77-C-01-4042

\section{Merget:}

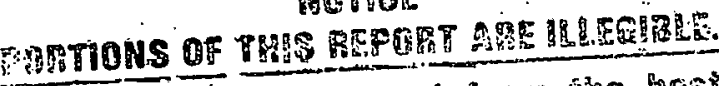

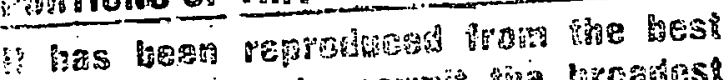
6. 
THIS PAGE

WAS INTENTIONALLY

LEFT BLANK 
PREFACE

The work documented here was performed by the SERI Renewable Resource Assessment Branch for the U.S. Department of Energy under Task No. 1093.00. The report compares several simple global hortzontal insolation models with several rigorous radiative transfer models and describes an improved, simple, global insolation model. We would like to thank J. V. Dave of IBM for providing data sets from his Spherical Harmonics code.

Richard E Bird

Richard E. Bird

Senior Scientist

Approved for

SOLAR ENERGY RESEARCH INSTITUTE

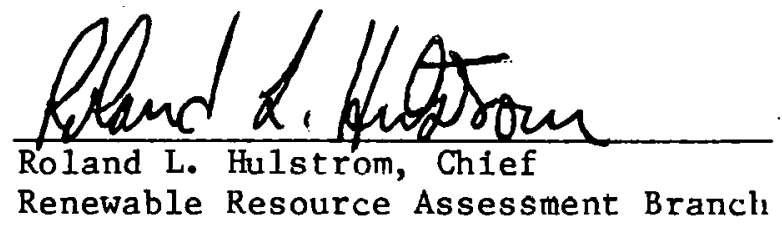

Barry 7 Buttes

Barry Butler, Manager

General Research Division

iii 
THIS PAGE

WAS INTENTIONALLY

LEFT BLANK 


\section{SUMMARY}

\section{OBJECTIVE}

This report presents the Bird model, a simple broadband model for direct and diffuse insolation under clear sky conditions. The model is based on comparisons with results from rigorous radiative transfer codes. The model is composed of simple algebraic expressions, and the inputs to the model are from readily avallable meteorological data. This enables the model to be implemented very easily.

\section{DISCUSSION}

The results of a detailed comparison of five simple broadband models for clear sky global insolation are presented here. These five models have appeared recently in publications, and many of them are widely used in the solar community. A sixth simple model, the Bird model, has been formulated that uses parts of the formalisms of these five models. This model is expected to provide greater accuracy and is still easy to implement and use.

\section{CONCLUSIONS}

All of the simple models compared here provide results that agree within $<10 \%$ with the results from three rigorous radiative transfer codes when the sun is in the zenith position. The Bird and Hoyt models agree within $3 \%$ with each other and with the results from the rigorous codes. However, the Bird model is the easier of the two models to implement. Future work will include comparisons with carefully taken insolation and meteorological data and the inclusion of the effects of clouds in the model. 
THIS PAGE

WAS INTENTIONALLY

LEFT BLANK 
TABLE OF CONTENTS

Page

1.0 Introduction......................................

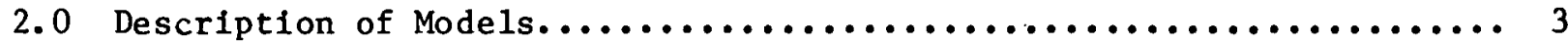

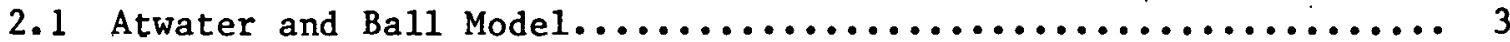

2.2 Davies and Hay Model. ................................ 4

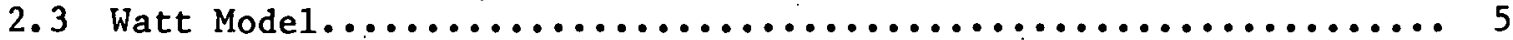

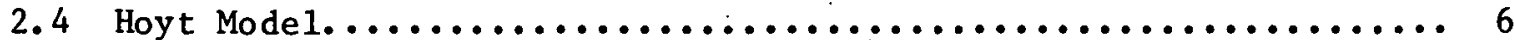

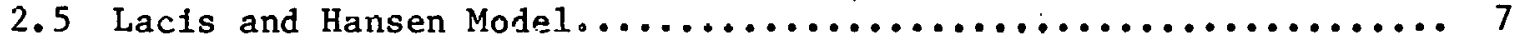

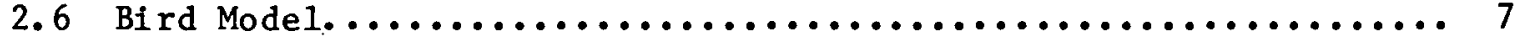

2.7 Rigorous Codes.................................. 10

3.0 Model Comparisons................................. 13

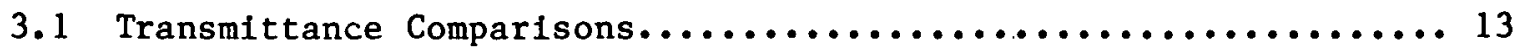

3.2 Irradiance Comparisons............................. 15

4.0 Summary and Conclusions............................ 27

5.0 References....................................... 29

Appendix A: Tabulated Model Data.......................... 31 
THIS PAGE

WAS INTENTIONALLY

LEFT BLANK 


\section{LIST OF FIGURES}

Page

3-1 Transmittance versus Secant of Solar Zenfth Angle for Midlatitude Summer Model....................................... 14

3-2 Aerosol Transmittance--USS Atmosphere (23-km-Visib1l1ty Aeroso1).... 16

3-3 Rayleigh Transmittance...............................16

3-4 Water Vapor Transmittance--USS Atmosphere $\left(1.42-\mathrm{cm} \mathrm{H}_{2} \mathrm{O}\right.$ in

Vertical Column)................................17

3-5 Ozone Transmittance--USS Atmosphere...................... 17

3-6 Tota1 Insolation--USS Atmosphere....................... 18

3-7 Direct Horizontal Insolation--USS Atmosphere................ 18

3-8 Diffuse Sky Insolation--USS Atmosphere...................... 19

3-9 Diffuse Ground/Sky Insolation--USS Atmosphere................. 19

3-10 Total Insolation--MLs Atmosphere....................... 21

3-11 Direct Horizontal Insolation--MLS Atmosphere................. 21

3-12 Diffuse Sky Insolation--MLs Atmosphere.................... 22

3-13 Diffuse Ground/Sky Insolation--MLS Atmosphere................ 22

3-14 Total Insolation--Dave Model $3 . \ldots \ldots \ldots \ldots \ldots \ldots \ldots \ldots \ldots \ldots \ldots \ldots \ldots$

3-15 Direcl Horizontal Insolatinn--Dave Model 3................. 23

3-16 Diffuse Sky Insolation--Dave Model 3..................... 24

3-17 Diffuse Ground/Sky Insolation--Dave Model 3.................. 24

3-18 Direct Norma1 Insolation--Dave Mode1 3.................... 26

3-19 Direct Normal Insolation--USS Atmosphere.................. 26 
THIS PAGE

WAS INTENTIONALLY

LEFT BLANK 


\section{LIST OF TABLES}

Page

2-1 Equations for Total Downward Irradiance for Atwater and Ball Mode1........................................ 3

2-2 Equations for Total Downward Irradiance for Davies and Hay Mode1.... 4

2-3 Equations for Total Downward Irradiance for Watt Mode1.......... 5

2-4. Equations for Total Downward Irradiance for Hoyt Model.......... 6

2-5 Equations for Total Downward Irradiance for Lacis and Hansen Model........................................ 7

2-6 Equations for Total Downward Irradiance for the Bird Model........ 8

2-7 Values of the Asymmetry Factor for the Rural and the Dave Haze L

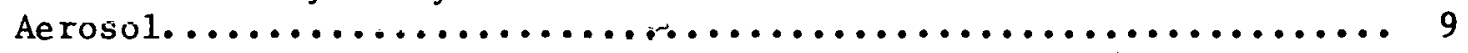

2-8 Input Parameters Required for Simple Models................. 10

3-1 Amounts of $\mathrm{H}_{2} \mathrm{O}$ and $\mathrm{O}_{3}$ in a Vertical Column for the MLS and USS

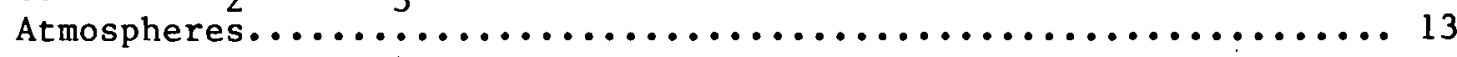

A-1 Tabulated Data from Several Models for the USS Atmosphere......... 33

A-2 Tabulated Data from Several Models for the MLS Atmosphere........ 35

A-3 Tabulated Data from Several Models for the Dave Model 3

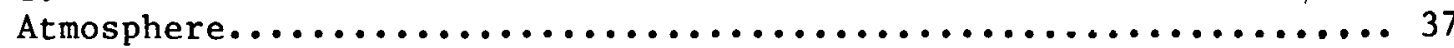


THIS PAGE

WAS INTENTIONALLY

LEFT BLANK 


\section{NOMENCLATURE}

$a_{1}$

$a_{\text {co }}$

$a_{\text {ox }}$

$a_{w}$

Ba

$F_{z j}$

$I_{\text {as }}$

$I_{d}$

$I_{G}$

$I_{s}$

$\mathrm{I}_{\mathrm{T}}$

$I_{0}$

$\mathrm{K}$

$\mathrm{K}_{1}$

M

$M^{\prime}$

$M_{i}$

$\mathbf{P}$

$r_{g}$

$r_{s}$

$\mathrm{T}$

ox

Absorptance parameters defined by Hoyt

Carbon dioxide absorptance

Oxygen absorptance

Water vapor absorptance

Ratio of the forward-scattered 1rradiance to the total scattered irradiance due to aerosols

A parameter used by Watt in air mass calculations

Solar Irradiance on a horizontal surface from atmospheric scattering $\left(\mathrm{W} / \mathrm{m}^{2}\right)$

Direct solar irradiance on a horizontal surface $\left(\mathrm{W} / \mathrm{m}^{2}\right)$

Solar irradiance on a horizontal surface from multiple reflections between the ground and sky $\left(\mathrm{W} / \mathrm{m}^{2}\right)$

Solar Irradiance on a horizontal surface from scattered light ( $I_{\text {as }}$ $+I_{G}$ )

Total (global) solar irradiance on a horizontal surface $\left(\mathrm{W} / \mathrm{m}^{2}\right)$

Extraterrestrial solar irradiance $\left(1353 \mathrm{~W} / \mathrm{m}^{2}\right)$

Aerosol transmittance for Davies and Hay

Constant used in Bird model associated with aerosol absorptance

A1 r mass

Pressure-corrected a1r mass

Watt's path length modifier (similar to air mass)

Surface pressure (mil11hars)

Ground albedo

Sky, or atmospheric, albedo

Surface temperature (K)

$\mathrm{T}_{\mathrm{A}}$. Transmittance of aerosol absorptance and scattering

$\mathrm{T}_{\mathrm{AA}} \quad$ Transmittance of aerosol absorptance 
$\Rightarrow=2$ in

$\begin{array}{ll}\mathrm{T}_{A S} & \text { Transmittance of aerosol scattering } \\ \mathrm{T}_{\text {as }} & \text { Transmittance of dry air absorptance and scattering for watt } \\ \mathrm{T}_{\mathrm{L}} & \text { Transmittance of lower layer aerosol for Watt } \\ \mathrm{T}_{\mathrm{M}} & \begin{array}{l}\text { Global transmittance of all molecular effects except water vapor } \\ \text { for Atwater }\end{array} \\ \mathrm{T}_{\mathrm{Md}} & \text { Direct transmittance of all molecular effects except water vapor } \\ & \text { for Atwater } \\ \mathrm{T}_{\mathrm{O}} & \text { Transmittance of ozone absorptance } \\ \mathrm{T}_{\mathrm{R}} & \text { Transmittance of Rayleigh scattering } \\ \mathrm{T}_{\mathrm{U}} & \text { Transmittance of upper layer aerosol for Watt } \\ \mathrm{T}_{\mathrm{UM}} & \text { Transmittance of absorptance of uniform1y mixed gases (carbon }\end{array}$ dioxlde and oxygen)

$T_{w} \quad$ Transmittance of water vapor absorptance $\left(1-a_{w}\right)$

$\mathrm{T}_{\mathrm{ws}} \quad$ Transmittance of water vapor scattering

$U_{0} \quad$ Amount of ozone in a vertical column from surface $(\mathrm{cm})$

$\tilde{U}_{\mathrm{W}} \quad$ Amount of precipitable water in a vertical column from surface $(\mathrm{cm})$

$\mathrm{x}_{\mathrm{n}} \quad$ Total amount of ozone in a s1anted path (cm)

$\mathrm{X}_{\mathrm{w}} \quad$ Total amount of precipitable water in a slanted path $(\mathrm{cm})$

Z Angle between a line to the sun and the local zenith (zenith angle in degrees)

$\alpha_{c s} \quad$ An actenuation multiplier used by watt

$\tau_{A} \quad$ Broadband aerosol optical depth from surface in a vertical path (broadband turbidity)

T0.5 Aerosol optical depth from surface in a vertical path at $0.5-\mu \mathrm{m}$ waveleng th

$\tau_{0.38}$ Aerosol optical depth from surface in a vertical path at $0.38-\mu \mathrm{m}$ wavelength

$\tau_{L} \quad$ Lower layer aerosol optical depth in a vertical path for Watt

$\tau_{\mathrm{u}} \quad$ Upper layer aerosol optical depth in a vertical path for Watt

Wo Single scattering albedo--the fraction of the light Jost from an incident pencil of radiation that is due to scattering 
SECTION 1.0

INTRODUCTION

To properly design a solar energy system for a location lacking an insolation data base, insolation models are required. This need for insolation models has been recognized for many years. One early and widely used insolation model was published in 1940 by Moon [1]. This model is still used today in its original or modified forms $[2,3]$.

Insolation models have proliferated to the point where it is difficult for a solar user to decide which model to adopt. The purpose of this paper is to provide a detailed comparison of several simple, broadband insolation models that are currently in use and, based on this comparison and comparisons with more rigorous radiative transfer models, to formulate a simple clear sky model for direct and diffuse insolation. This type of comparison should be helpful in evaluating the relative accuracy of various models and give direction for formulating a model that uses the best of each existing model. The criteria used for evaluating and formulating models have been simplicity, accuracy, and the ability to use readily available meteorological data.

It should be noted that the use of the word "rigorous" does not necessarily mean that the "rigorous" results truly represent reality. Even though these "rigorous" codes are very detailed in the methods used to solve the radiative transfer problem, the representativeness of the results depends upon how well the atmospheric model, the measured atmospheric parameters, the mathematical methods, and other assumptions made in the codes relate to a real situation. However, in the absence of wel1-documented data, this approach of using "rigorous" codes as a basis of comparison was used. 


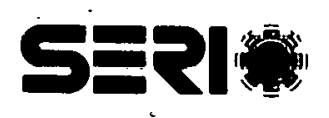


SECTION 2.0

\section{DESCRIPTION OF MODELS}

A brief description of the several models that have been compared is presented here. Further details of this comparison can be found in Ref. 4 and in the original publications of each author. Most of the models include the effect of clouds, but this aspect of the models is not included here. Comparisons of cloud-cover global insolation models will follow (in a subsequent report) the clear sky model comparisons reported here. Such comparisons have also been performed by Davies and Hay [5].

\subsection{ATWATER AND BALİ MODEL}

Direct and global insolation models were published by Atwater and $\mathrm{Ba} 11$ $[6,7]$. The direct insolation model was taken from Kastrov as discussed by Kondratyev [8]. The equations of transfer and the transmission functions for this insolation model are given in Table 2-1. (The symbols in Tables 2-1 through 2-6 are defined in the Nomenclature.)

Table 2-1. EQUATIONS FOR TOTAL DOWNWARD IRRADIANCE FOR ATWATER AND BALL MODEL

Basic Equations

$$
\begin{aligned}
& \mathrm{I}_{\mathrm{d}}=\mathrm{I}_{\mathrm{o}}(\cos \mathrm{Z})\left(\mathrm{T}_{\mathrm{Md}}-\mathrm{a}_{\mathrm{w}}\right) \mathrm{T}_{\mathrm{A}} \\
& \mathrm{I}_{\mathrm{T}}=\mathrm{I}_{\mathrm{O}}(\cos \mathrm{Z})\left(\mathrm{T}_{\mathrm{M}}-\mathrm{a}_{\mathrm{w}}\right) \mathrm{T}_{\mathrm{A}} /\left(1-\mathrm{r}_{\mathrm{g}} \mathrm{r}_{\mathrm{s}}\right)
\end{aligned}
$$

Transmission Functions

$$
\begin{aligned}
T_{M d} & =1.041-0.16\left[M\left(949 \times 10^{-6} P+0.031\right)\right]^{0.5} \\
T_{M} & =1.021-0.0824\left[M\left(949 \times 10^{-6} P+0.051\right)\right]^{0.5} \\
a_{w} & =0.077\left(U_{W^{M}}\right) 0.3 \\
T_{A} & =\exp \left(-\tau A^{M^{\prime}}\right) \\
M & =35 /\left[\left(1224 \cos ^{2} Z\right)+1\right]^{0.5} \\
M^{\prime} & =P M / 1013
\end{aligned}
$$

The form of the equation for water vapor absorption "was published by McDonald [9]. The value of $r_{s}=0.0685$ for a molecular atmosphere, as reported by Lacis and Hansen [10], was used with this model. Atwater and Ball 
used MIE calculations to obtain $\tau_{A}$, which is much too rigorous for a simple model. Therefore, a value of $\tau_{A}$ that will be described later in the Bird model was used here.

\subsection{DAVIES AND HAY MODEL}

A model for solar insolation (direct and diffuse) was published by Davies and Hay [5]. The equations used in this model were partially the result of comparing several existing models, and they are presented in Table 2-2.

Table 2-2. EQUATIONS FOR TOTAL DOWNWARD IRRADIANCE FOR DAVIES AND HAY MODEL

Basic Equations

$$
\begin{aligned}
& I_{d}=T_{0}(\cos Z)\left(T_{0} T_{R}{ }_{W}\right) T_{A} \\
& I_{a s}=I_{0}(\cos z)\left[T_{0}\left(1-T_{R}\right) T_{A}(0.5)+\left(T_{O} T_{R}-a_{W}\right)\left(1-T_{\Lambda}\right) W_{o} B_{a}\right] \\
& I_{G}=r_{g} r_{s}\left(I_{d}+I_{a s}\right) /\left(1-r_{g} r_{s}\right) \\
& I_{T}=I_{d}+I_{a s}+I_{G}
\end{aligned}
$$

Transmission Functions

$$
\begin{aligned}
& \mathrm{T}_{\mathrm{o}}=1-0.02118 \mathrm{x}_{\mathrm{o}} /\left(1+0.042 \mathrm{x}_{\mathrm{o}}+0.000323 \mathrm{x}_{\mathrm{o}}^{2}\right) \\
& -1.082 \mathrm{x}_{n} /\left(1+138.6 \mathrm{x}_{\mathrm{o}}\right)^{0.8005}-0.0658 \mathrm{x}_{0} /\left[1+\left(103.6 \mathrm{x}_{\mathrm{o}}\right)^{3}\right] \\
& \mathrm{X}_{\mathrm{O}}=\mathrm{U}_{\mathrm{O}} \mathrm{M} \\
& \mathrm{a}_{\mathrm{w}}=2.9 \mathrm{x}_{\mathrm{w}} /\left[\left(1+141.5 \mathrm{x}_{\mathrm{w}}\right)^{0.635}+5.925 \mathrm{x}_{\mathrm{w}}\right] \text {. } \\
& \mathrm{X}_{\mathrm{w}}=\mathrm{U}_{\mathrm{w}} \mathrm{M} \\
& \mathrm{T}_{\mathrm{A}}=\mathrm{K}^{\mathrm{M}} \\
& r_{s}=0.0685+\left(1-B_{a}\right)\left(1-T_{A}\right) W_{o}
\end{aligned}
$$

The expressions for ozone transmittance, $T_{o}$, and water vapor absorption, $a_{w}$, were taken from Lacis and Hansen [10]. The transmission due to Rayleigh ecattering, $T_{R}$, was presented in tabular form, and so we used the Bird mode1 expression for $T_{R}$ in this model. The value $K=0.91$ was used for data generated here and is representative of aerosol conditions in southern Ontario. $\mathrm{W}_{\mathrm{o}}=0.98$ and $\mathrm{B}_{\mathrm{a}}=0.85$ were used here also. 


\subsection{WATT MODEL}

Another direct and diffuse insolation model has been constructed by Watt [3], based partially on the work of Moon [1]. The equations for this model are shown in Table 2-3.

Table 2-3. EQUATIONS FOR TOTAL DOWNWARD IRRADIANCE FOR WATT MODEL

\section{Baslc Equations}

$$
\begin{aligned}
I_{d}= & I_{0}(\cos Z) T_{w a} T_{a s} T_{o} T_{w s} T_{L} T_{U} \\
I_{s}= & I_{0}\left[0.8 r_{s}\left(1+r_{g} r_{s}\right)(1+\cos Z)^{0.5}\right. \\
& \left.\quad+0.5 \alpha_{c s} r_{g} r_{s} \cos Z+0.5 r_{s} \cos Z\right]
\end{aligned}
$$

\section{Transmission Functions}

$$
\begin{aligned}
& \mathrm{T}_{\mathrm{w}}=0.93-0.033 \log \left(\mathrm{U}_{\mathrm{w}} \mathrm{M}_{2}\right) \\
& \mathrm{T}_{\text {as }}=10^{-0.045\left[\left(\mathrm{P} / \mathrm{P}_{\mathrm{o}}\right) \mathrm{M}_{1}\right]^{0.7}} \\
& \mathrm{~T}_{0}=10^{-\left(0.0071+0.01 \mathrm{U}_{0} \mathrm{M}_{4}\right)} \\
& \mathrm{T}_{\mathrm{wS}}=10^{-\left(0.0095 \mathrm{U}_{\mathrm{w}} \mathrm{M}_{2}\right)} \\
& \mathrm{T}_{\mathrm{L}}=10^{\tau} \mathrm{L}^{\mathrm{M}_{2}}{ }^{0.7} \\
& \mathrm{~T}_{\mathrm{U}} \quad=10^{-\tau} \mathrm{u}_{3} \\
& \tau_{\mathrm{L}}=0.6\left(\tau_{0.5}-0.01 \mathrm{U}_{\mathrm{W}}-0.03\right) \\
& \alpha_{c s}=\left(0.93-0.033 \log \mathrm{U}_{\mathrm{W}}\right) 10^{-\left[0.006 \mathrm{P} / 1013+0.4 \cdot\left(\mathrm{T}_{\mathrm{L}}+\mathrm{T}_{\mathrm{u}}\right)\right]} \\
& \mathrm{r}_{\mathrm{s}}=\alpha_{\mathrm{cs}}\left\{1-10^{-\left[0.003 \mathrm{P} / 1013+0.01 \mathrm{U}_{\mathrm{w}}+0.4\left(\mathrm{~T}_{\mathrm{L}}+\mathrm{T}_{\mathrm{U}}\right)\right]}\right\} \\
& M_{i} \quad=\sec Z \text { for } z \leqslant 70^{\circ}(i=1,2,3,4) \\
& M_{i}=\left(h_{2} F_{z 2}-h_{1} F_{z l}\right) /\left(h_{2}-h_{1}\right) \text { for } z>70^{\circ}(i=1,2,3,4) \\
& F_{z j}=\left\{\left[\left(r / h_{j}\right) \cos z\right]^{2}+2 r / h_{j}+1\right\}^{0.5}-\left(r / h_{j}\right) \cos z \quad(j=1,2) \\
& \text { for } i=1, h_{1}=0 . \mathrm{km} \text { and } h_{2}=30 \mathrm{~km} \\
& i=2, h_{1}=0 \mathrm{~km} \text { and } h_{2}=3 \mathrm{~km} \\
& i=3 ; h_{1}=15 \mathrm{~km} \text { and } h_{2}=25 \mathrm{~km} \\
& i=4, h_{1}=20 \mathrm{~km} \text { and } h_{2}=40 \mathrm{~km}
\end{aligned}
$$


The upper layer broadband turbidity, $\tau_{u}$, was not well defined by Watt. A value of $\tau_{u}=0.02$ was used in the calculations performed here, which appears to be an average value for locations in the United States. The parameter $r$ is the earth's radius $\left(6.4 \times 10^{6} \mathrm{~m}\right)$.

\subsection{HOYT MODEL}

The equations used in the model by Hoyt [11] are shown in Table 2-4.

Table 2-4. EQUATIONS FOR TOTAL DOWNWARD IRRADIANCE FOR HOYT MODEL

Basic Equations

$$
\begin{aligned}
& I_{d}=I_{0}(\cos 7)\left(1-\sum_{i=1}^{5} a_{i}\right) T_{\Lambda \varepsilon} T_{R} \\
& I_{a s}=I_{0}(\cos Z)\left(1-\sum_{i=1}^{5} a_{i}\right)\left[\left(1-T_{R^{\prime}}\right) 0.5+\left(1-T_{A S}\right) 0.75\right] \\
& I_{G}=\left(I_{d}+I_{a s}\right) r_{g}\left(1-\sum_{i=1}^{5} a_{i}^{\prime}\right)\left[\left(1-T_{R^{\prime}}\right) 0.5+\left(1-T_{A S^{\prime}}\right) 0.25\right] \\
& I_{T}=I_{d}+I_{a s}+I_{G}
\end{aligned}
$$

Transmission Functions

$$
\begin{aligned}
& a_{1}=a_{w}=0.110\left(0.75 U_{w^{M}}+6.31 \times 10^{-4}\right) 0.3-0.0121 \\
& a_{2}=a_{c o}=0.00235\left(126 M^{\prime}+0.0129\right)^{0.26}-7.5 \times 10^{-4} \\
& a_{3}=\left(1-T_{0}\right)=0.045\left(U_{0} M+8.34 \times 10^{-4}\right)^{0.38}-3.1 \times 10^{-3} \\
& a_{4}=a_{O X}=7.5 \times 10^{-3}\left(M^{\prime}\right)^{0.875} \\
& a_{5}=0.05 T_{A S} \\
& M^{\prime}=M P / 1013.25
\end{aligned}
$$

Hoyt obtained alr mass values, M, from Bemporad's [12] tables. The expression for air mass of Kasten [13] was used here instead. The values of $T_{A S}$ and $T_{R}$ are calculated from tables furnished by Hoyt [11]. The $a_{i}$ ' values are calculated using air mass values of $M^{\prime}+1.66 \mathrm{P} / 1013.25$ in the $a_{1}$ expressions. 
$\mathrm{T}_{\mathrm{AS}}$ ' and $\mathrm{T}_{\mathrm{R}}{ }^{\prime}$ are evaluated for air mass values of $1.66 \mathrm{P} / 1013.25$ in $\mathrm{T}_{\mathrm{AS}}$ and $\mathrm{T}_{\mathrm{R}^{*}}$ The table values from which $\mathrm{T}_{\mathrm{AS}}$ is calculated are limited so that large optical depths cannot be considered. Large optical depths can occur from high turbidity or from large zenith angles. In the data presented later for $\mathrm{z}=$ $80^{\circ}$, an approximate value of $\mathrm{T}_{\mathrm{AS}}$ was used to complete the plotted results.

\subsection{LACIS AND HANSEN MODEL}

The equations for the model developed by Lacts and Hansen [10] are shown in Table 2-5.

Table 2-5. EQUATIONS FOR TOTAL DONNHARD IRRADIANCE FOR LACIS AND HANSEN MODEL

Basic Equation

$$
I_{T}=I_{0}(\cos z)\left[\left(0.647-r_{s}^{\prime}-a_{0}\right) /\left(1-0.0685 r_{g}\right)+0.353-a_{w}\right]
$$

Transmission Functions

$$
\begin{aligned}
r_{s}^{\prime}= & 0.28 /(1+6.43 \cos \mathrm{Z}) \\
a_{0}= & 1-T_{0} \text { as shown in Table } 2-2 \\
a_{w}= & \text { Shown in Table } 2-2 \text { with the following correction: } \\
& x_{w}=X_{w}(P / 1013)^{0.75}(273 / T)^{0.5}
\end{aligned}
$$

\subsection{BI RD MODEL}

A model has been constructed that is based on comparisons with the SOLTRAN 3 and SOLTRAN 4 [4] direct insolation models and the BRITE Monte Carlo global model.[14]. Formalisms in the previous models that were considered to be optimum were adopted here. The equations for this model are shown in Table 2-6.

The atmospheric turbidity values, $\tau$ A, 0.38 and $\tau_{A}, 0,5$, have been measured on a regular basis by the National Weatther Service [15] at $0.38-$ and $0.5-\mu \mathrm{m}$ wavelengths, respectively. If one of the turbidity values is not available, its value can be entered as a zero in the expression for ${ }^{\top} A^{*}$ The expression for ${ }^{\tau} A$ is based on the Air Force Geophysics Laboratory (AFGL) rural aerosol mode1 [16]. The expression used here for $\mathrm{T}_{\mathrm{AA}}$ was found by fitting the expression to the results of the SOLTRAN 4 [4] code. The value of $K_{1}=0.0933$ for the rural aerosol was used here for all calculations. For the urban aerosol model, which contains more carbon, the value of $\mathrm{K}_{1}=0.385$ was found to be appropriate. From a theoretical standpoint, $K_{1}$ should be nearly equal to $1-W_{0}$, where $W_{0}$ is the single scattering albedo. The forward-scattering 
Table 2-6. EQUATIONS FOR TOTAL DOWNWARD IRRADIANCE FOR THE BIRD MODEL

Basic Equations

$$
\begin{aligned}
I_{d}= & I_{0}(\cos Z)(0.9662) T_{R} T_{o} T_{U M} T_{w} T_{A} \\
I_{a s}= & I_{0}(\cos Z)(0.79) T_{0} T_{w} T_{U M} T_{A A} \\
& {\left[0.5\left(1-T_{R}\right)+B_{a}\left(1-T_{A S}\right)\right] /\left[1-M+(M)^{1.02}\right] } \\
& \ddots \\
I_{T}= & \left(I_{d}+I_{a s}\right) /\left(1-r_{g} r_{s}\right)
\end{aligned}
$$

Transmission Equations

$$
\begin{aligned}
& T_{R}=\exp \left\{-0.0903\left(M^{\prime}\right)^{0.84}\left[1+M^{\prime}-\left(M^{\prime}\right)^{1.01}\right]\right\} \\
& \mathrm{T}_{0}=1-0.1611 \mathrm{x}_{0}\left(1+139.48 \mathrm{x}_{0}\right)^{-0.3035} \\
& -0.002715 x_{0}\left(1+0.044 x_{0}+0.0003 x_{0}^{2}\right)^{-1} \\
& \mathrm{X}_{\mathrm{O}}=\mathrm{U}_{\mathrm{O}} \mathrm{M} \\
& \mathrm{T}_{\mathrm{UM}}=\exp \left[-0.0127\left(\mathrm{M}^{\prime}\right)^{0.26}\right] \\
& \mathrm{T}_{\mathrm{w}}=1-2.4959 . \mathrm{X}_{\mathrm{w}}\left[\left(1+79.034 \mathrm{X}_{\mathrm{w}}\right)^{0.6828}+6.385 \mathrm{X}_{\mathrm{v}}\right]^{-1} \\
& \mathrm{X}_{\mathrm{W}}=\mathrm{U}_{\mathrm{W}} \mathrm{M} \\
& \mathrm{T}_{\mathrm{A}}=\exp \left[\tau_{\mathrm{A}} \mathrm{U.8/3}\left(1+\mathrm{r}_{\mathrm{A}}-\tau_{\mathrm{A}}{ }^{0.7088}\right) \mathrm{M}^{0.9108}\right] \\
& \tau_{\mathrm{A}}=0.2758 \tau_{\mathrm{A}, 0.38}+0.35 \tau_{\mathrm{A}, 0.5} \\
& \mathrm{~T}_{\mathrm{AA}}=1-\mathrm{K}_{1}\left(1-\mathrm{M}+\mathrm{M}^{1.06}\right)\left(1-\mathrm{T}_{\mathrm{A}}\right) \\
& T_{A S}=T_{A} / T_{\Lambda \Lambda} \\
& \mathbf{r}_{s}=0.0685+\left(1-B_{a}\right)\left(1.0-r_{a s}\right) \\
& M=\left[\cos z+0.15(93.885-z)^{-1.25}\right]^{-1} \\
& M^{\prime} \quad=M P / 1013
\end{aligned}
$$

ratio; $B_{a}$, is related through MIE theory to a parameter $\langle\cos \theta\rangle$, called the asymmetry factor, by

$$
B_{a}=0.5(1+\langle\cos \theta\rangle)
$$


The asymmetry factor is the mean of the cosine of the scattering angle, $\theta$, with the angular intensity as the weighting function. The extreme values of $\mathrm{B}_{\mathrm{a}}$ are

$$
\mathrm{B}_{\mathrm{a}}=\left\{\begin{array}{l}
1 \text { for all forward scattering; } \\
0.5 \text { for isotropic scattering; } \\
0 \text { for all backward scattering. }
\end{array}\right.
$$

Table 2-7 contains values of the asymmetry factor at various wavelengths for the rural aerosol model and the haze $\mathrm{L}$ aerosol model used by Dave [17]. Two differences in these aerosol models are: (1) the rural aerosol model is bimodal, whereas Dave's model has a single mode; and (2) the rural aerosol model varies the complex index of refraction with wavelength, and the Dave model holds it constant. The values of the asymmetry factors for the two models are in reasonably good agreement, and our calculations indicate that the Bird model is relatively insensitive to small changes in this parameter. $A$ value of $B_{a}=0.82$ was used for the rural aerosol, and $B_{a}=0.86$ for Dave's aerosol in calculations shown later.

Table 2-7. VALUES OF THE ASYMMETRY FAC'IOR FOR THE RURAL AND THE DAVE HAZF. L AEROSOL

\begin{tabular}{lllll}
\hline \multicolumn{2}{c}{ Rural } & & \multicolumn{2}{c}{ Dave Haze L } \\
\cline { 5 - 6 } \multicolumn{1}{c}{\langle} & $\langle\cos \theta\rangle$ & & \multicolumn{1}{c}{$\lambda$} & $\langle\cos \theta\rangle$ \\
\hline 0.325 & 0.66 & & -- & -- \\
0.35 & 0.66 & & 0.35 & 0.73 \\
0.4 & 0.65 & & -- & -- \\
0.5 & 0.64 & & 0.455 & 0.72 \\
0.63 & 0.64 & & 0.635 & 0.71 \\
0.7525 & 0.63 & & 0.7525 & 0.71 \\
0.86 & 0.63 & & -- & -- \\
0.9935 & 0.63 & & 0.994 & 0.70 \\
1.235 & 0.64 & & 1.235 & 0.69 \\
1.497 & 0.65 & & 1.61 & 0.67 \\
1.8 & 0.68 & & 2.1 & 0.63 \\
2.198 & 0.71 & & 2.198 & 0.62 \\
\hline
\end{tabular}

It is suggested that values of $B_{a}=0.84$ and $K_{1}=0.1$ be used with this model unless good information on the aerosol is available. All other data required by the model comes from meteorological measurements near the site of interest.

Ozone measurements are sometimes difficult to obtain. Since ozone has a minor effect on broadband solar insolation, it is suggested that the method of Van Heukion [18] could be used in lieu of real data. 
The expression used for air mass in the Bird model comes from Kasten [13] and was used for all of the calculations reported here except for the Atwater and Ball model and the Watt model.

For the convenience of the reader, Table 2-8 itemizes the input parameters required for each of the simple models.

Table 2-8. INPUT PARAMETERS REQUIRED FOR SIMPLE MODELS

\begin{tabular}{|c|c|}
\hline Mode1 & Input \\
\hline $\begin{array}{l}\text { Atwater } \\
\text { and } \\
\mathrm{Ba} 11\end{array}$ & $\begin{array}{l}\text { Snlar conetant, ecnith anyle, surface pressure, } \\
\text { ground albedo, prertpitablo watcr vapor, tulal } \\
\text { ozone, broadband turbidity }\end{array}$ \\
\hline $\begin{array}{l}\text { Davies } \\
\text { and } \\
\text { Hay }\end{array}$ & $\begin{array}{l}\text { Solar constant, zenith angle, surface pressure, } \\
\text { ground albedo; precipitable water vapor, total } \\
\text { ozone, aerosol single scattering albedo ( } 0.98 \\
\text { suggested), aerosol forward scattering ratio } \\
(0.85 \text { suggested), broadband aerosol transmittanse }\end{array}$ \\
\hline Watt & $\begin{array}{l}\text { Solar constant, zenith angle, surface pressure, } \\
\text { ground albedo, precipitable water vapor, total } \\
\text { ozone, turbidity at } 0.5-\mu \mathrm{m} \text { wavelength, upper } \\
\text { layer turbidity }\end{array}$ \\
\hline Hoyt & $\begin{array}{l}\text { Solar constant, zenith angle, surface pressure, } \\
\text { ground albedo, precipitable water vapor, total } \\
\text { uzune, rurbidity at one wavelength }\end{array}$ \\
\hline $\begin{array}{l}\text { Lacis } \\
\text { and } \\
\text { Hansen }\end{array}$ & $\begin{array}{l}\text { Solar constant, zenith angle, surface pressure, } \\
\text { surface temperature, ground albedo, preclpitable } \\
\text { water vapor, total ozone }\end{array}$ \\
\hline Bird & $\begin{array}{l}\text { Solar constant, zcnith angle, surface pressure, } \\
\text { ground albedo, precipitable water vapor, total } \\
\text { ozone, turbidity at } 0.5-\text { and/or } 0.38-\mu m \text { wave- } \\
\text { length, aerosol forward scattering ratio ( } 0.84 \\
\text { recommended) }\end{array}$ \\
\hline
\end{tabular}

\subsection{RIGOROUS CODES}

Three rigorous codes have been used in this study, as a basis for formulating the Bird model. One code is for direct normal irradiance and is called SOLTRAN 4 [4]. Two other codes, which include both the direct normal and the diffuse irradiance, are the BRITE [14] Monte Carlo code and the Dave [17] Spherical Harmonics code. In each of these codes, a multilayered atmospheric model can be constructed, where important atmospheric parameters are defined 
at each layer. In this way, a fairly detailed atmosphere can be constructed that closely resembles the real atmosphere at a given time and specific location. Each code then uses its own technique to solve the radiative transfer problem.

These rigorous codes calculate the irradiance at a specified altitude, sun angle, and for an atmospheric model at discrete wavelengths. For comparison with the simple broadband models described previously, the spectral irradiance from the rigorous codes has to be integrated over wavelength.

The SOLTRAN 3 code, an earlier version of SOLTRAN 4, was used to formulate most of the transmittance functions found in the Bird mode1. This was accomplished by performing a least-square fit of each transmittance function to transmittance data from SOLTRAN 3 for each atmospheric constituent. Further details of this operation can be found in Ref. 4. SOLTRAN 3 was used because it was the only version avallable to us when this portion of the work was performed. The only difference in the two models that would be apparent in the results would be. caused by a slight difference in the "continental" and "rural" aerosol models that are used in the two codes.

A comparison was made between data from the BRITE code and several of the simple clear sky global models. Based on this comparison and the author's judgment of the best expressions used in the simple models, a model for the diffuse irradiance was formulated. This simple model of the diffuse irradiance was then fine-tuned to provide good agreement with the BRITE code as well as results from the Dave Spherical Harmonics code.

It is appropriate to comment here that there are problems with the expressions used for the diffuse irradiance model. The general formalism for the diffuse transfer equation of some of the simple models was adopted even though it may not be as acceptable, based on the physics of the problem, as one would like. For example, a cosine of the solar zenith angle is included in the diffuse transfer equation. This implies that all of the diffuse radiation behaves just like the direct normal component. The cosine is used to calculate the irradiance falling on a horizontal surface. However, it is well known that the diffuse irradiance is much more complex than this. An example of a more rigorous but fafrly simple formalism for the diffuse irradiance is found in Ref. 19, in which the diffuse radiation is divided into three components: an isotropic term, a term resulting from horizon brightening, and a circumsolar term. The circumsolar term is the only one that behaves very much like the direct normal radiation. For tilted surfaces, a ground reflection should be added to this diffuse model. Another problem with this formalism is associated with using transmittance expressions for diffuse radiation that were derived for direct radiation. 
SFR눈 
SECTION 3.0

MODEL COMPARISONS

Each of the simple models described in Section 2.0 was programmed on a computer to produce data for comparison. A comparison of the aerosol transmittance, the transmittance after molecular (Rayleigh) scattering, the water vapor $\left(\mathrm{H}_{2} \mathrm{O}\right)$ transmittance, and the ozone $\left(\mathrm{O}_{3}\right)$ transmittance will be presented first. Then, a comparison between the direct, the diffuse sky, the diffuse sky/ground, and the global radiation for three different atmospheric models will be shown. Comparisons are made, where possible, between each of the simple model results as well as the results from the rigorous models.

\subsection{TRANSMI TTANCE COMPARISONS}

To become orfented as to the relative importance of each atmospheric constituent in atmospheric transmittance, the broadband transmittance versus the secant of the solar zenith angle (approximate air mass) for each constituent was plotted in Fig. 3-1. This figure was generated with output from the SOLTRAN 3 code for a Midlatitude Summer (MLS) atmospheric model. Table 3-1 shows the amounts of $\mathrm{H}_{2} \mathrm{O}$ and $\mathrm{O}_{3}$ from sea level to the top of the atmosphere in a vertical column for the two atmospheric modcls--MLS and USS (U.S. Standard)-used in this comparison.

Table 3-1. AMOUNTS OF $\mathrm{H}_{2} \mathrm{O}$ AND $0_{3}$ IN A VERTICAL COLUMN FOR THE MLS AND USS ATMOSPHERES

\begin{tabular}{ccc}
\hline & $\begin{array}{c}\mathrm{H}_{2} \mathrm{O} \\
(\mathrm{cm})\end{array}$ & $\begin{array}{c}\mathrm{O}_{3} \\
(\mathrm{~cm})\end{array}$ \\
\hline MLS & 2.93 & 0.31 \\
USS & 1.42 & 0.34 \\
\hline
\end{tabular}

An examination of. Fig. 3-1 shows that $\mathrm{CO}_{2}$ and $\mathrm{O}_{2}$ are the least important attenuators, and this is why they are not included in some models. The next element exhibiting increased attenuation is $\mathrm{O}_{3}$, followed by $\mathrm{H}_{2} \mathrm{O}$. Molecular scattering dominates the total molecular absorption at large zentth angles and has a greater effect than most individual molecular species at all zenith angles. The most significant attenuator at all zenith angles is the aerosol. The aerosol modeled here was the continental aerosol model [16] with a sea level meteorological range of $23 \mathrm{~km}$. A 23-km meteorological range is considered to be a moderately clear atmosphere. This aerosol produces an optical depth of 0.27 (basc e) at $0.5-11 \mathrm{~m}$ wavelength. 


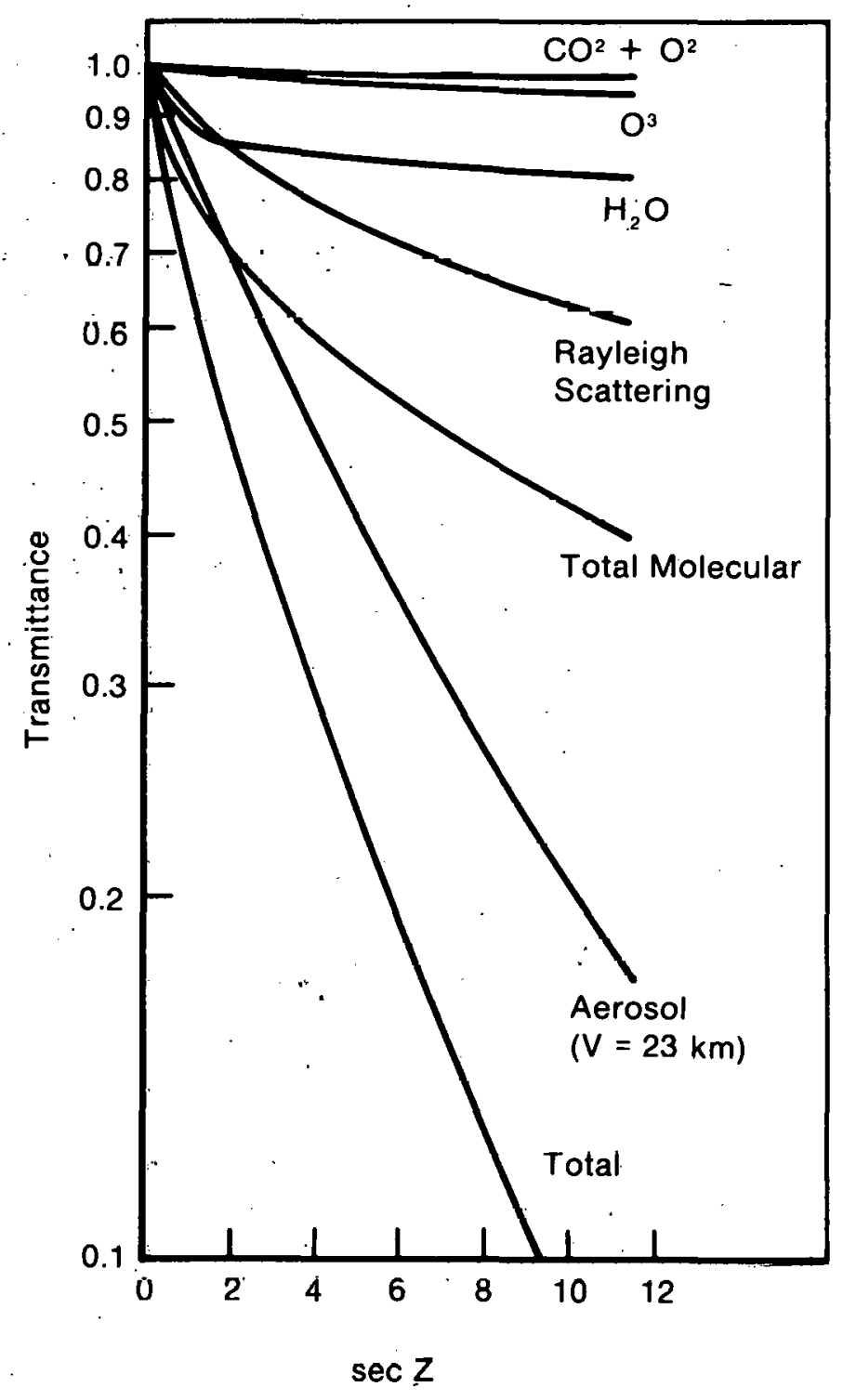

Figure 3-1. Transmittance versus Secant of Solar Zenith Angle for Midlatitude Summer Model 
The data in Fig. 3-1 indicate the relative effect that the atmospheric constituents have on the direct irradiance. However, when global irradiance is being considered these results can be misleading. A large fraction of the radiation lost in the direct beam by molecular and aerosol scattering is regained in the diffuse component. As a result of this, changes in aerosol optical depth through the atmosphere have less effect on the total global irradiance than on the direct irradiance.

Figures 3-2 and 3-5 present transmittance data for the USS atmosphere from several of the models. It should be pointed out that the broadband turbidity expression from the Bird model was used in the Atwater and Ball mode1. A similar effort could have been made with the aerosol transmittance term in the Davies and Hay model to produce identical results. One of the strengths of the Bird model is that it is based entirely on algebraic expressions for transmittance calculations rather than tabulated data. This makes the use of the model considerably easier and provides more flexibility.

The comparison made here for one model atmosphere is not really indicative of the accuracy of each model. Since a wide range of values of turbidity, $\mathrm{H}_{2} \mathrm{O}$ amount, and $\mathrm{O}_{3}$ amount are required for real atmospheric conditions, the model must be able to accommodate these changes. Additional comparisons are presented in Ref. 4 for a range of these parameters. As was stated earlier, the transmittance expressions in the Bird model were derived from comparisons with SOLTRAN 3 results, but the comparieons made here are with SOLTRAN 4 results. This should have an effect only on the aerosol transmittance shown in Fig. 3-2. The transmittance comparisons shown in Figs. 3-2 through 3-5 are rather self-explanatory, and so no further discussions are presented.

\subsection{IRRADIANCE COMPARISONS}

The global solar irradiance has been divided into three components: the direct irradiance on a horizontal surface, the diffuse sky irradiance on a hortzontal surface, and the diffuse ground/sky irradiance on a horizontal surface. The diffuse sky irradiance is the total diffuse radiation present when the ground has zero albedo (completely absorbing ground), and the diffuse ground/sky irradiance is that amount added to the total diffuse irradiance when the ground albedo is not zero.

Figures 3-6 through 3-9 present comparisons of the global irradiance at sea level in the USS atmosphere from all of the models as well as comparisons of the three components of the global irradiance. For this atmospheric model, the Bird, Hoyt, and Monte Carlo models produce very similar results. The model of Atwater and $\mathrm{Ba} 11$ significantly underestimates the diffuse sky irradiance, and the watt model overestimates the diffuse sky irradiance. The results of the Davies and Hay model would have shown much better agreement with the Monte Carlo results if a more reasonable value of the aerosol transmittance had been used. The Bird model Rayleigh transmittance was used in the Davies and Hay model.

It is instructive to examine the relalive magnitude of each romponent. For a solar zenith angle of zero (the sun directly overhead), the direct component provides approximately $81 \%$ of the total, the diffuse sky approximately $17 \%$, 
$\Rightarrow=1{ }^{\prime \prime}$

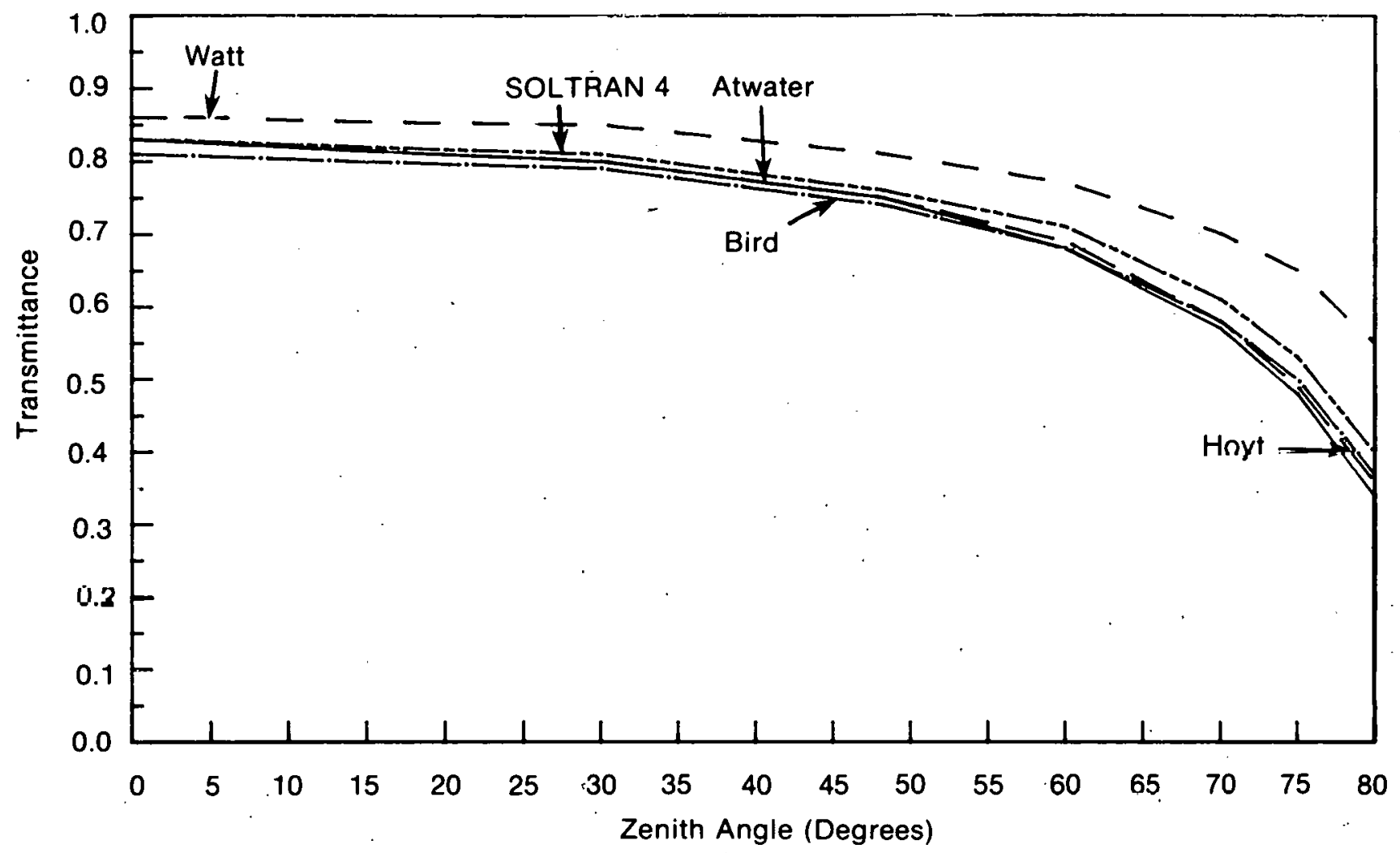

Figure 3-2. Aerosol Transmittance - USS Atmosphere (23-km-Visibility Aerosol)

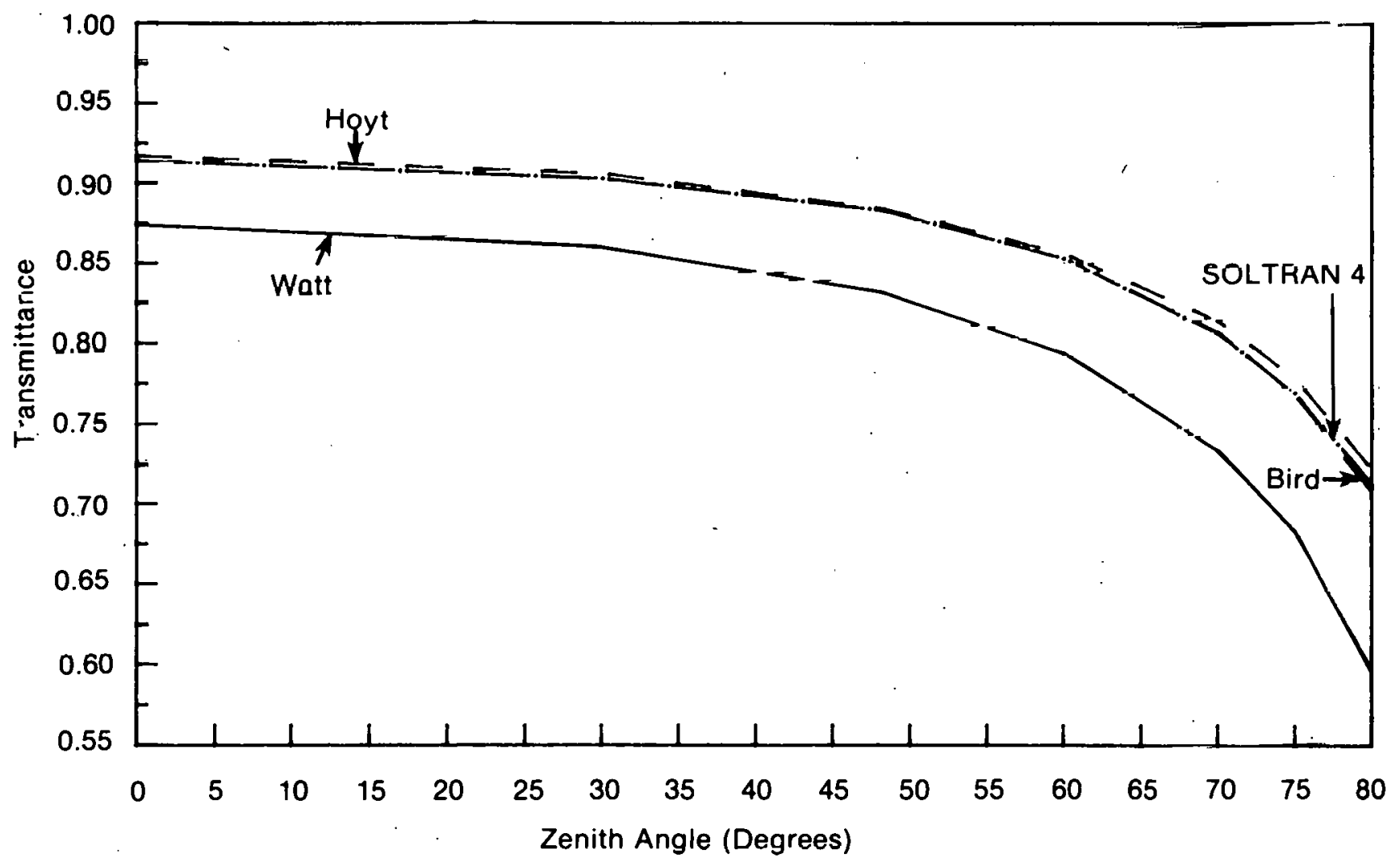

Figure 3-3. Rayleigh Transmittance 
SEPI

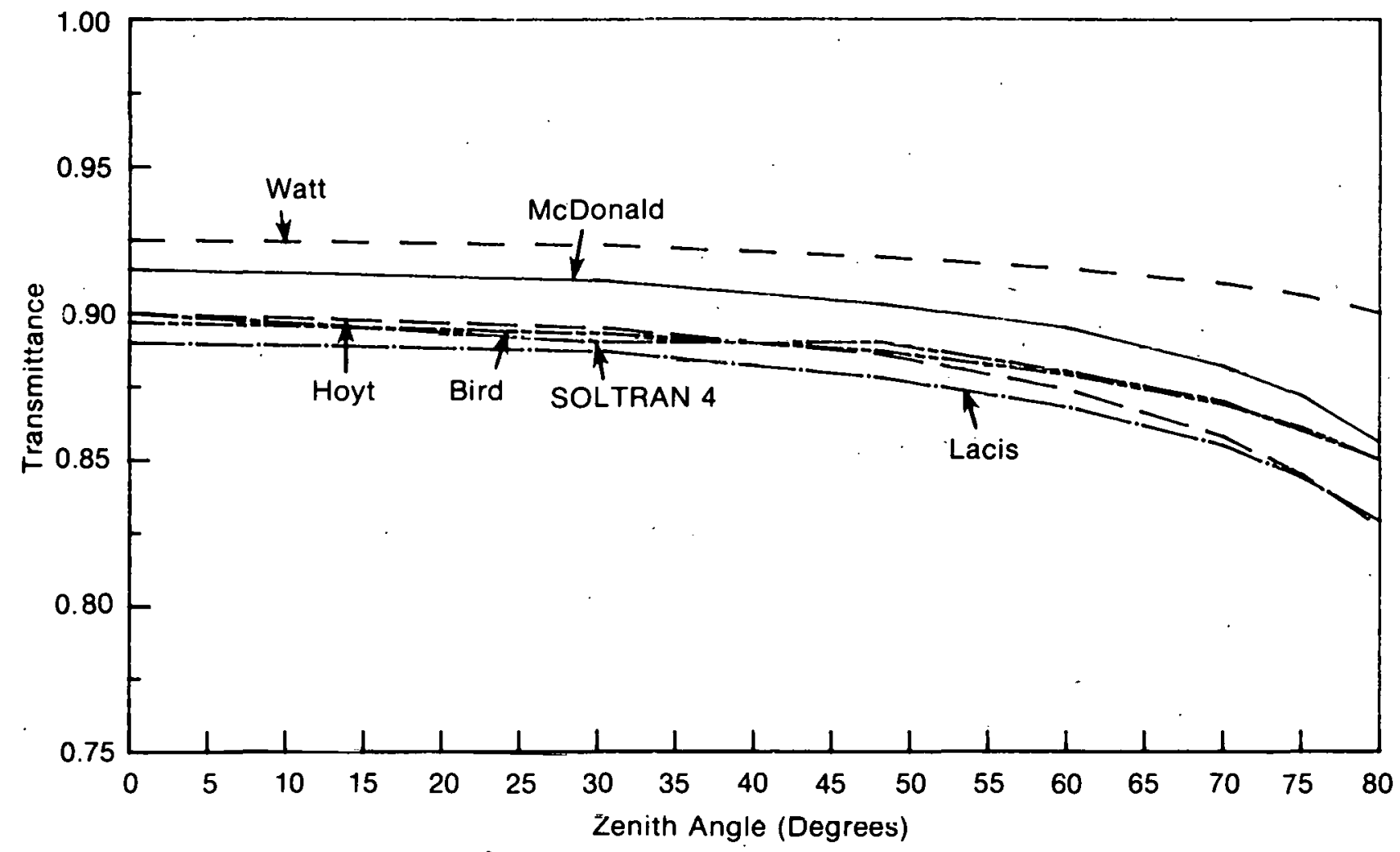

Figure 3-4. Water Vapor Transmittance - USS Atmosphere (1.42-cm $\mathrm{H}_{2} \mathrm{O}$ in Vertical Column.)

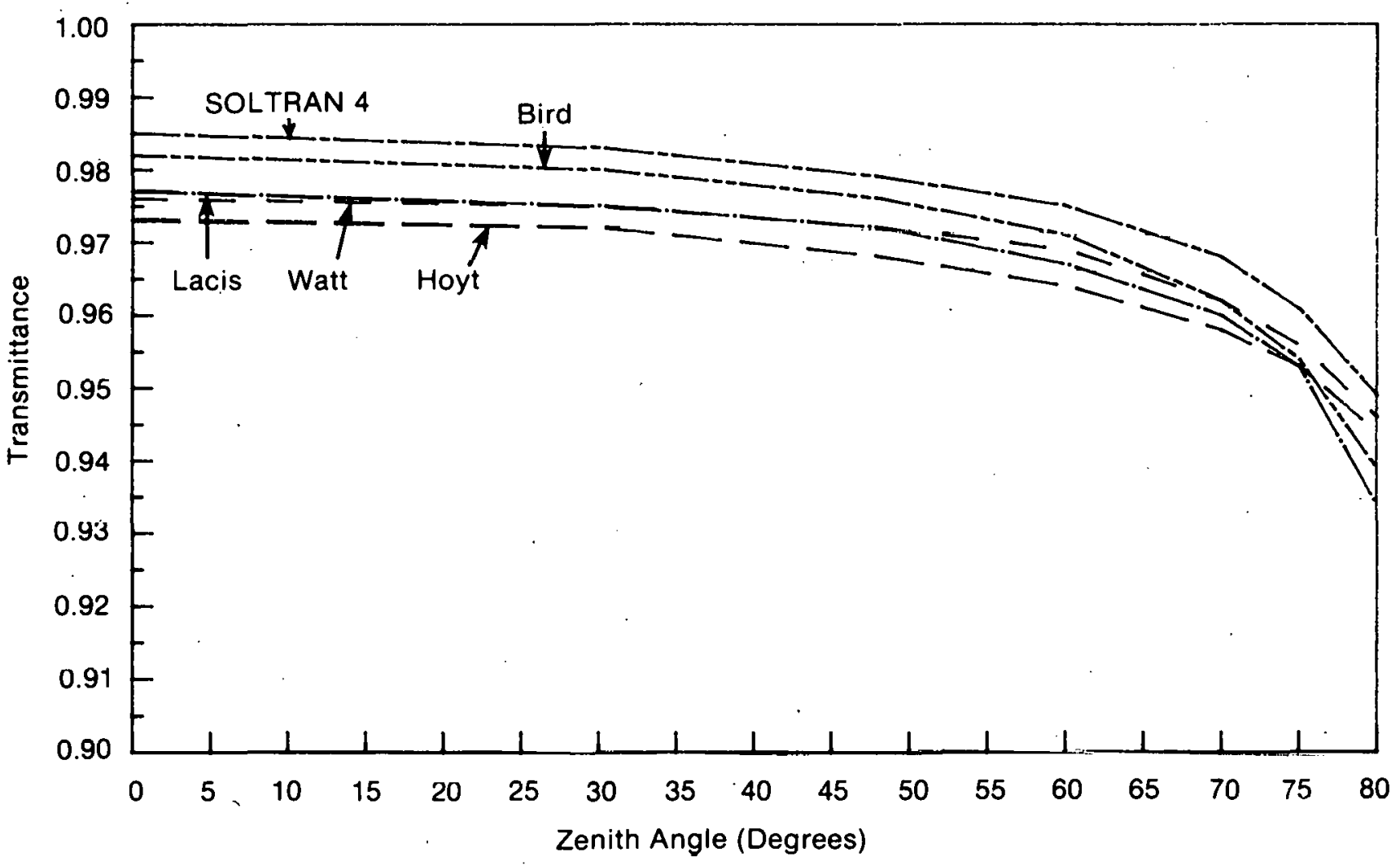

Figure 3-5. Ozone Transmittance - USS Atmosphere 
$x=$.
-0.

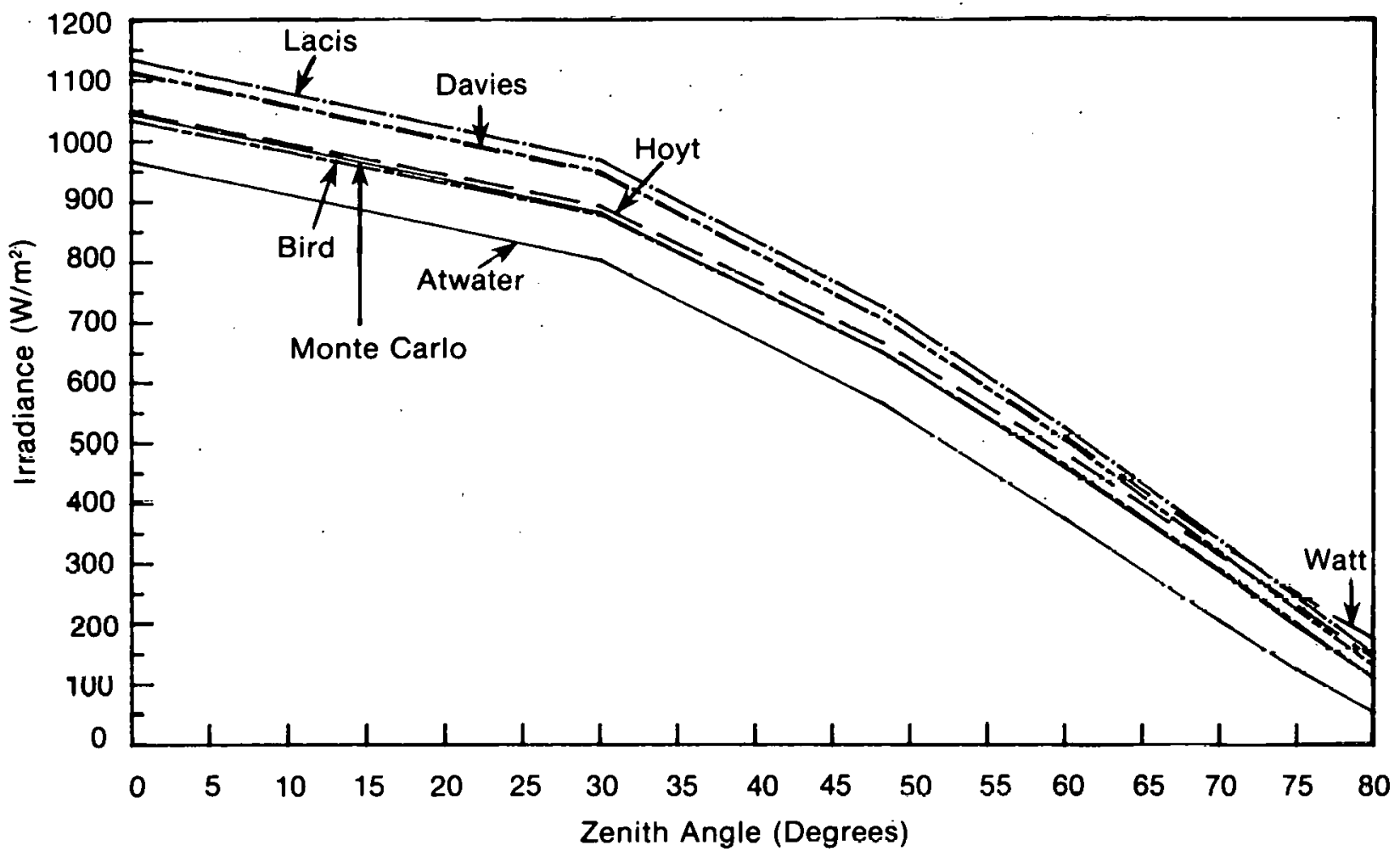

Figure 3-6. Total Insolation - USS Atmosphere (23-km-Visibility Rural Aerosol, Albedo $=0.2$ )

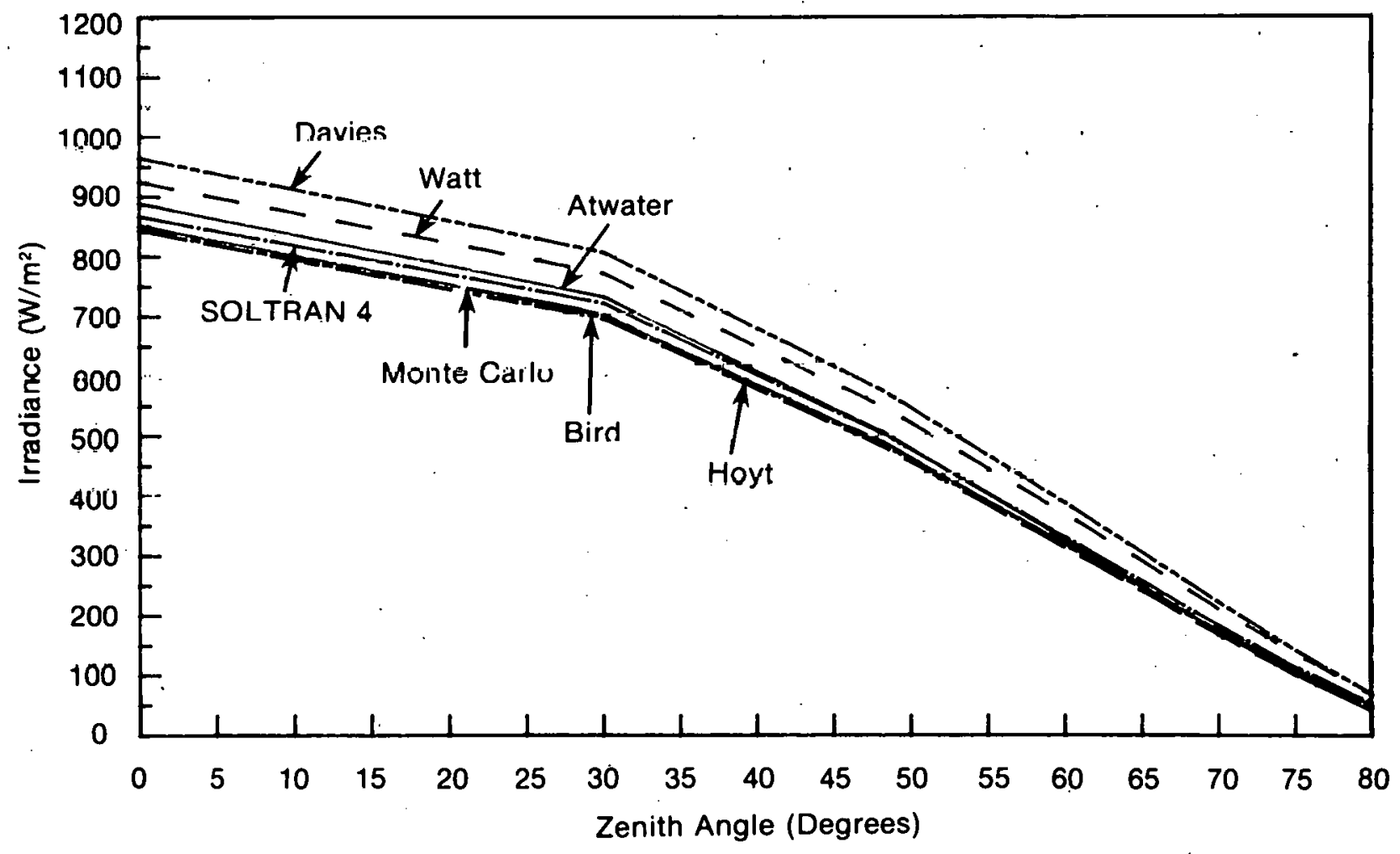

Figure 3-7. Direct Horizontal Insolation - USS Atmosphere (V $=23 \mathrm{~km}$; $U_{W}=1.42 \mathrm{~cm} ; U_{0}=0.34 \mathrm{~cm}$ ) 
SEP1

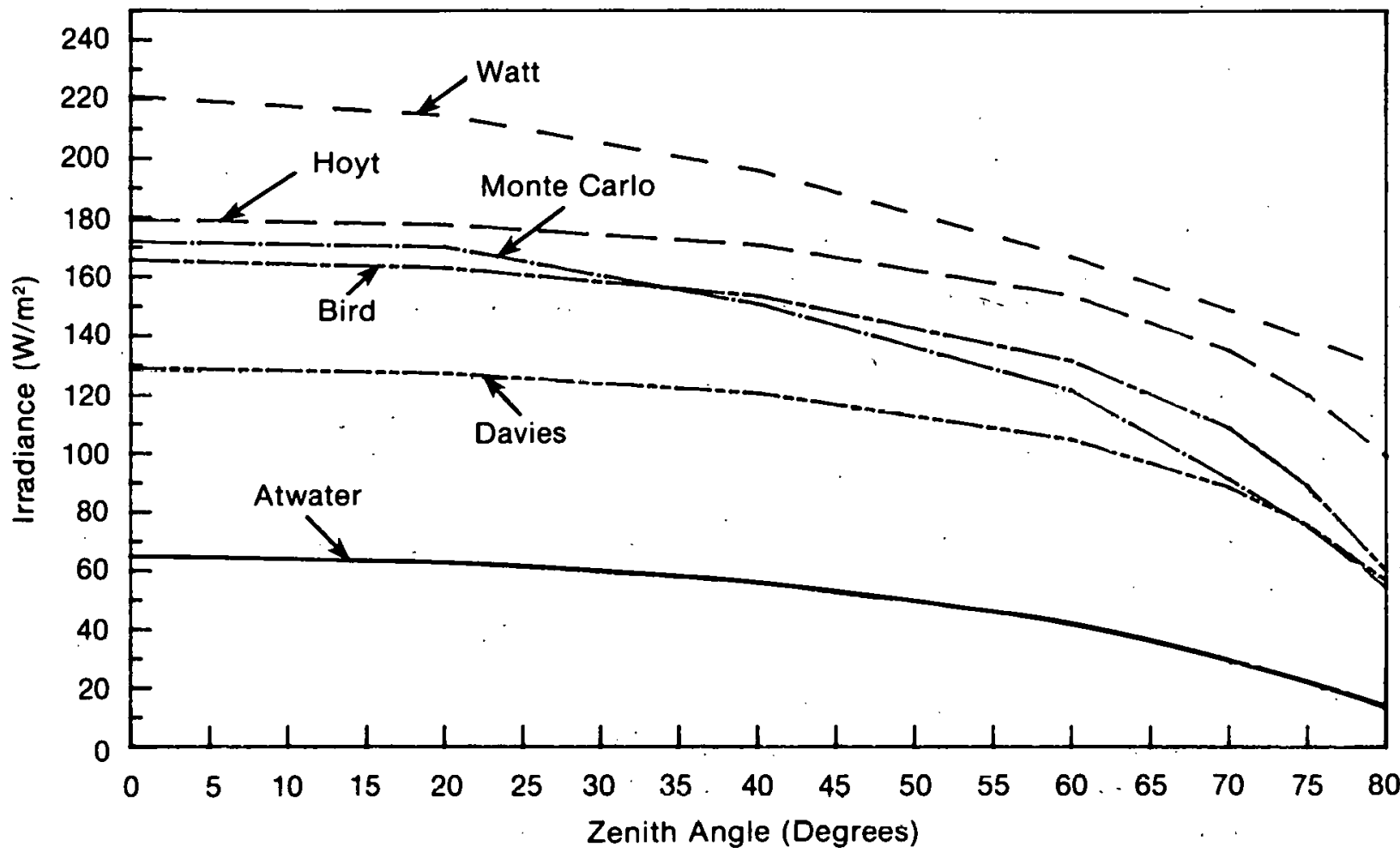

Figure 3-8. Diffuse Sky Insolation - USS Atmosphere (V = 23 km; $U_{w}=1.42 \mathrm{~cm} ; U_{0}=0.34 \mathrm{~cm}$ )

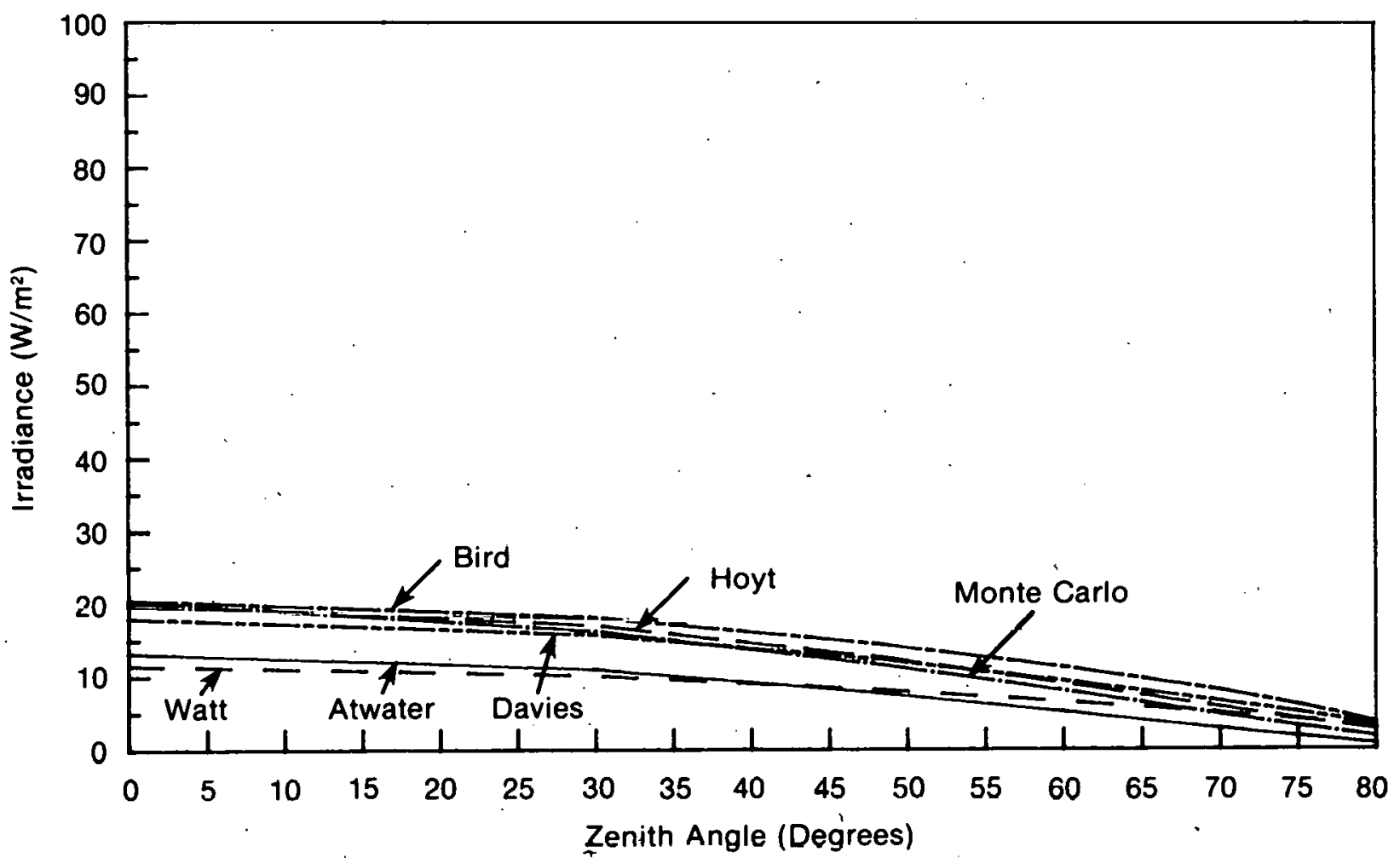

Figure 3-9. Diffuse Ground/Sky Insolation - USS Atmosphere (23-km-Visibility Rural Aerosol, Albedo $=0.2$ ) 
and the diffuse ground/sky approximately $2 \%$. The calculations are for a turbidity of 0.27 at $0.5-\mu \mathrm{m}$ wavelength and a ground albedo of 0.2 .

In Figures 3-10 through 3-13, a similar set of plots is presented for the MLS atmospheric model with an atmospheric turbidity of 0.27 at $0.5-\mu \mathrm{m}$ wavelength and a ground albedo of 0.8. The larger ground albedo increases the diffuse ground/sky component by a factor of four. It is evident that the simple models begin to deviate from the Monte Carlo result for the diffuse ground/sky component. However, since this component is so small, the global result is still in close agreement. The relative agreement of the results from the different models is nearly the same as with the USS atmosphere. This is principally because the aerosol model is identical in both models.

Finally, a comparison is made of the models for the MI.S atmoopherc with the Haze $L$ aerosol model of Dave [17]. The Dave atmosphere modeled here consists of 15 homogeneous layers instead of the 32 exponentially varying layers that were used in the previous MLS atmosphere. In addition, the Haze L derusol model is signiflcantly different from the rural aerosol model used previously. Not only are the particle size distributions and complex indlces of refraction different, but most importantly the number density of the aerosol as a function of altitude is very different. The turbidity of this model is 0.0996 instead of the 0.266 used previously in the vicinity of $0.5-\mu \mathrm{m}$ wavelength. Calculations with SOLTRAN 4 show that a turbidity of 0.0996 in the rural aerosol model corresponds to a sea level visibility of nearly $250 \mathrm{~km}$. This is an extremely clear atmosphere. Figures 3-14 through 3-17 illustrate the comparison results for this atmospheric model.

It is readily apparent from the reculto shown in Figs. 3-14 chrough 3-1/ that the Atwater and $\mathrm{Ba} 11$ model is based on a very clear atmosphere, since it agrees much better with the Dave data. Similarly, the aernanl parameter, $\mathrm{K}=0.91$, used in the Davies and Hay model io for a vely s:1err armosphere. The Lacls and Hansen model appears to be in slightly cinser agreement with this clear atmosphere also, but it does not have provisions for changes in turbidity.

The clear sky diffuse irradiance of the Atwater and Ball model as shown in the figures-presented here may be slightly lower than the model intended because of the way the calculations were performed. This model is really composed of two separate models: one for the direct irradiance and one for the global irradiance. The clear sky diffuse irradiance was obtained by running the model for a ground albedo of zero and then subtracting the direct hor1zontal from the global. If the direct horizontal irradiance is slightly high, ns it a.p" pears to be, then the diffuse term would be slightly lower than expected. The real evaluation of this model should be made on the global horizontal irradiance.

It will be noted in Fig. 3-14 that there is a slight difference between the Monte Carlo global and the spherical harmonic global results of Dave ( 3.6\% at a zenith angle of 0 ). Figure 3-15 shows that a large fraction of this difference is in the direct component. Since the direct component of the Monte Carlo code is deterministic in nature rather than statistical, these differences are most likely due to differences in the molecular absorption coefficients used and the band absorption models used. Dave used an older set 


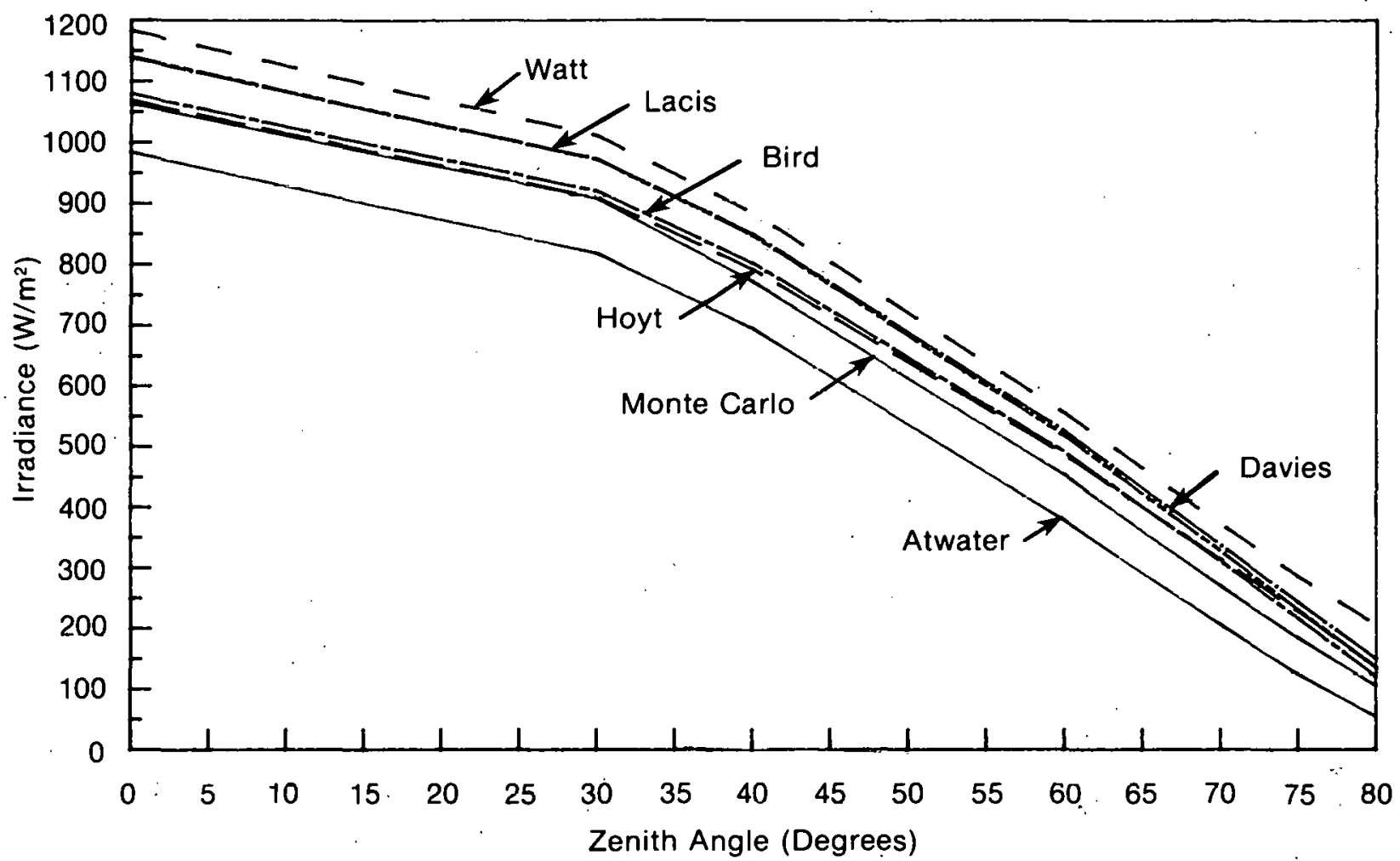

Figure 3-10. Total Insolation - MLS Atmosphere (23-km-Visibility Rural Aerosol, Albedo $=0.8$ )

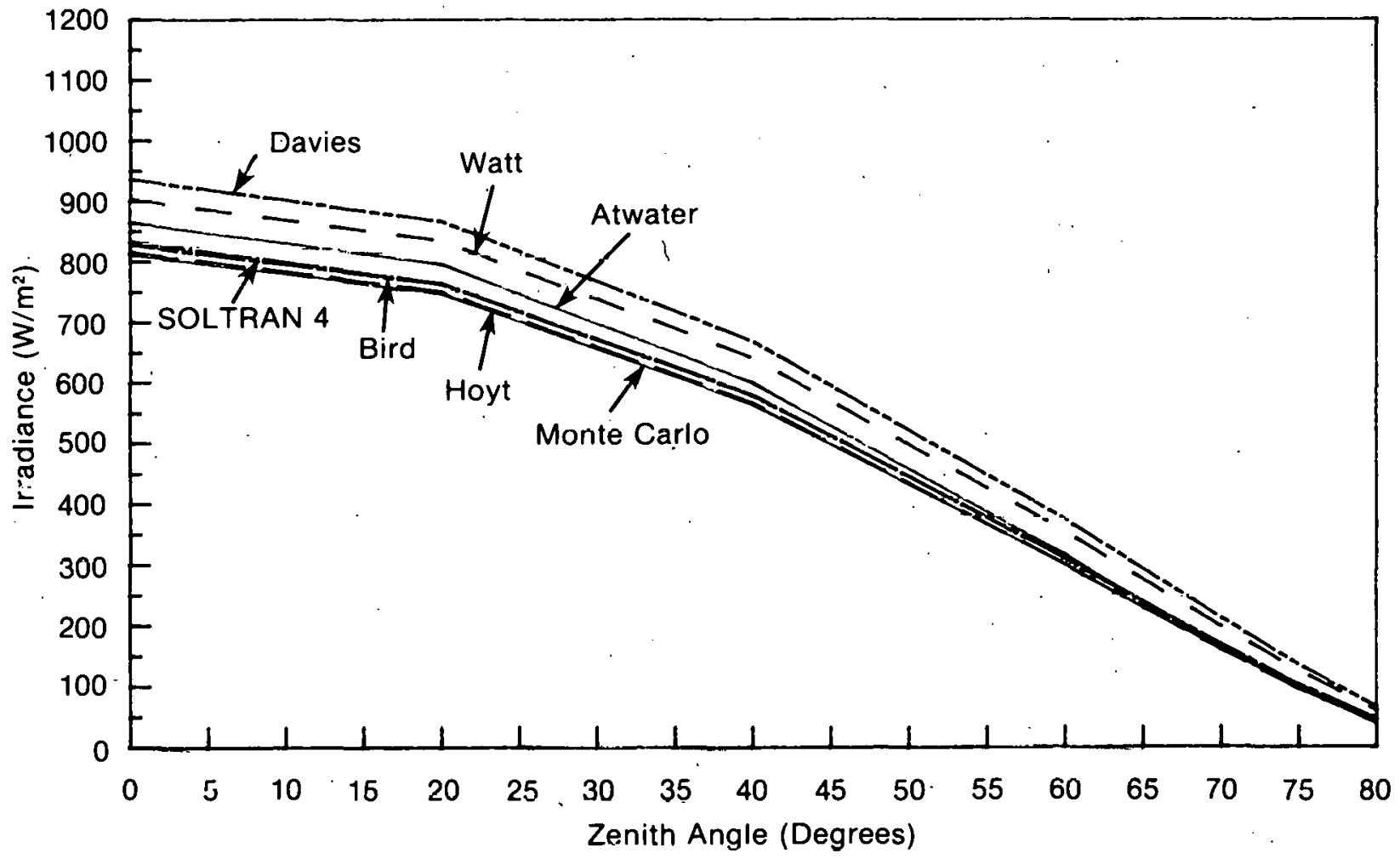

Figure 3-11. Direct Horizontal Insolation - MLS Atmosphere $\left(V=23 \mathrm{~km}, U_{W}=2.93 \mathrm{~cm}, U_{0}=0.31 \mathrm{~cm}\right)$ 


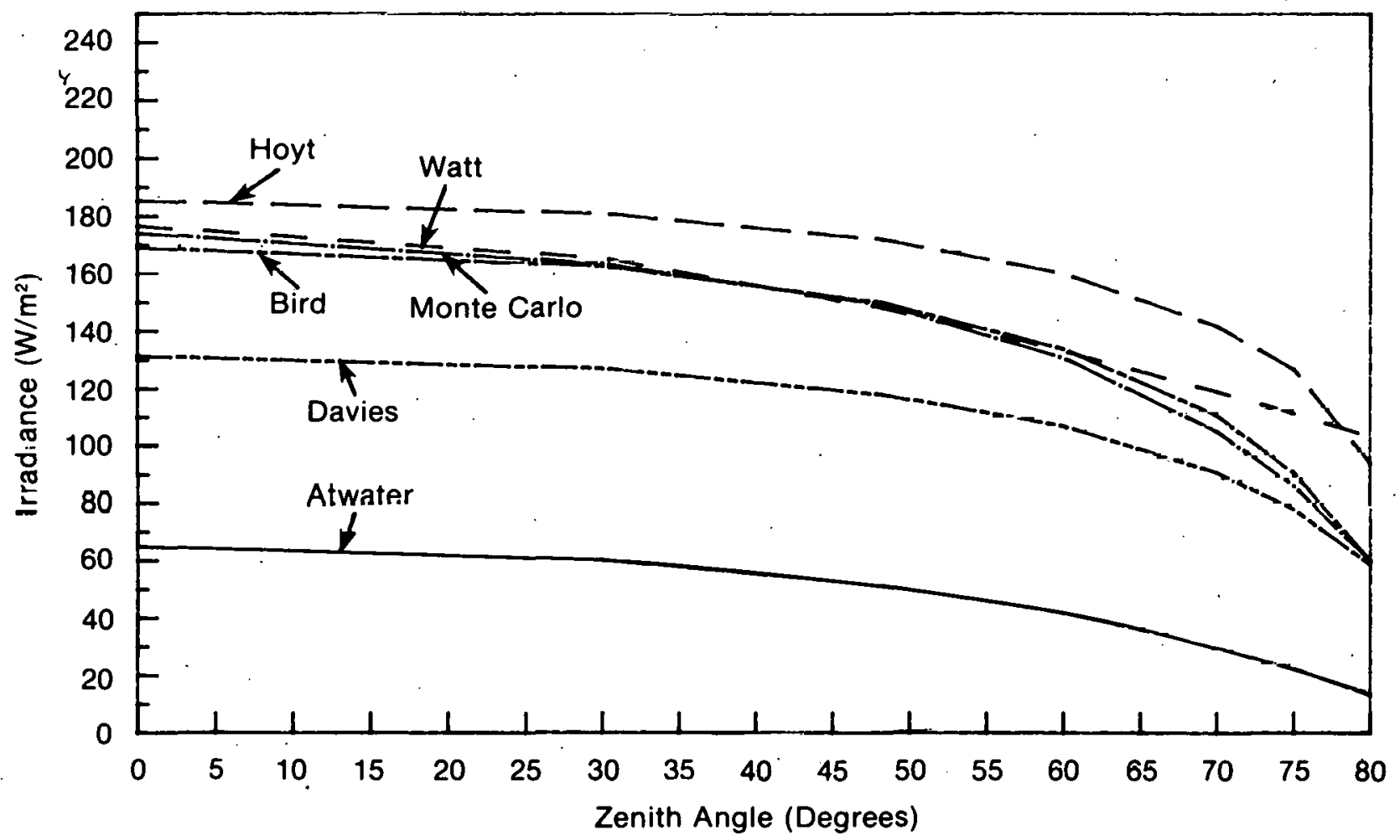

Figure 3-12. Diffuse Sky Insolation - MLS Atmosphere (V = $23 \mathbf{~ k m}$, $\left.U_{w}=2.93 \mathrm{~cm}, U_{0}=0.31 \mathrm{~cm}\right)$

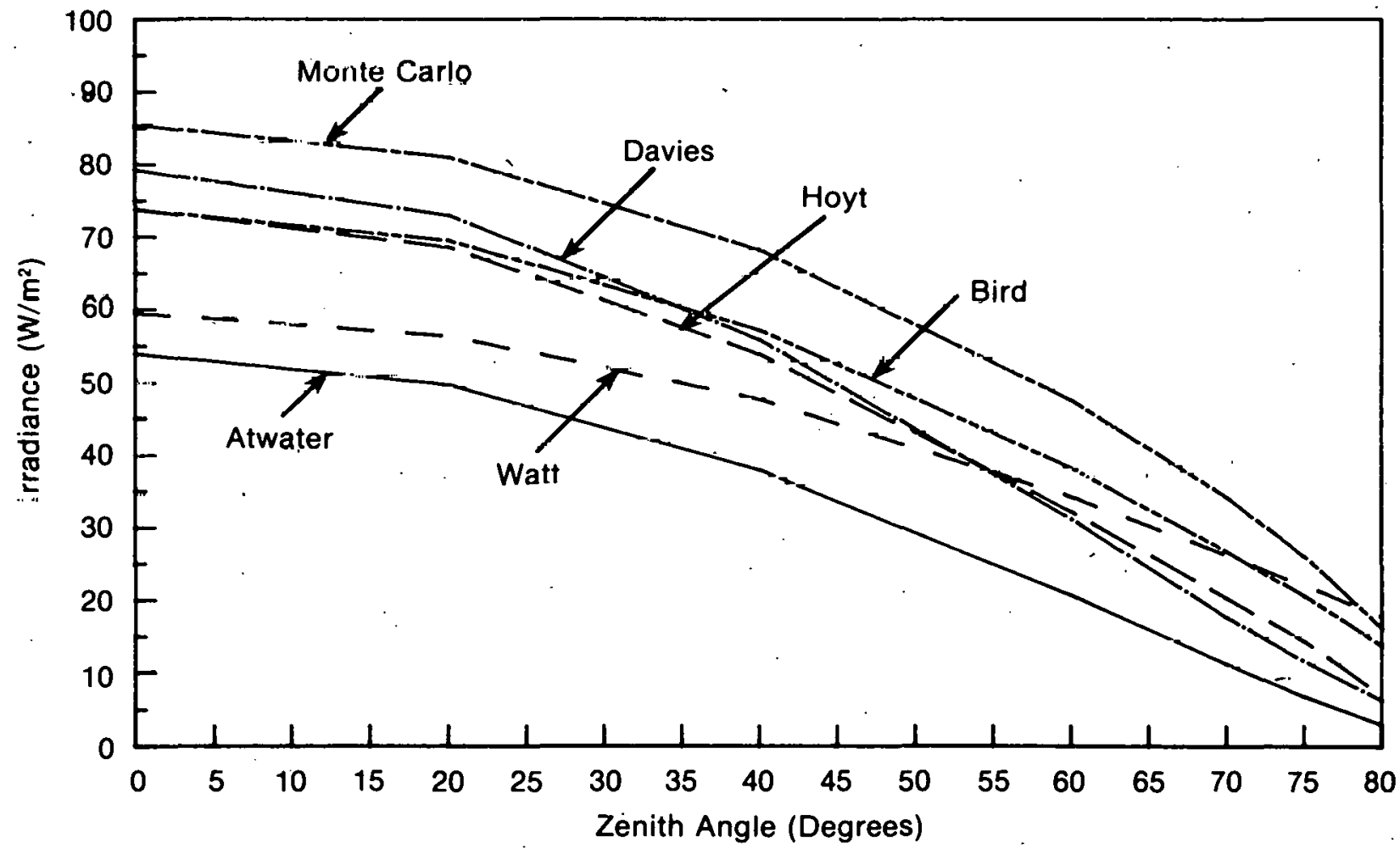

Figure 3-13. Diffuse Ground/Sky Insolation - MLS Atmosphere (23- km-Vislbility Rural Aerosol, Albedo $=0.8$ ) 


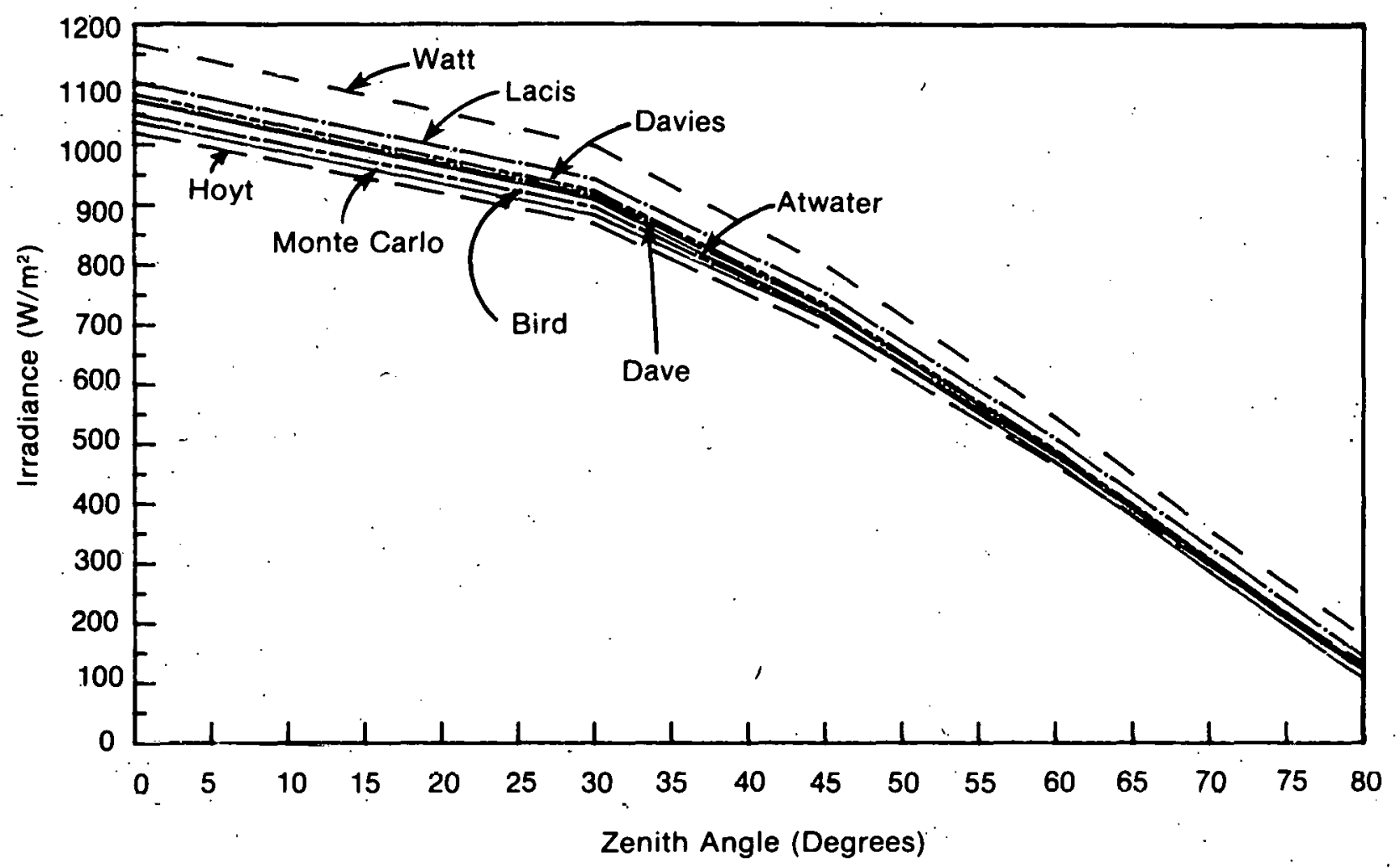

Figure 3-14. Total Insolation-Dave Model 3

(Albedo $=0.2)$

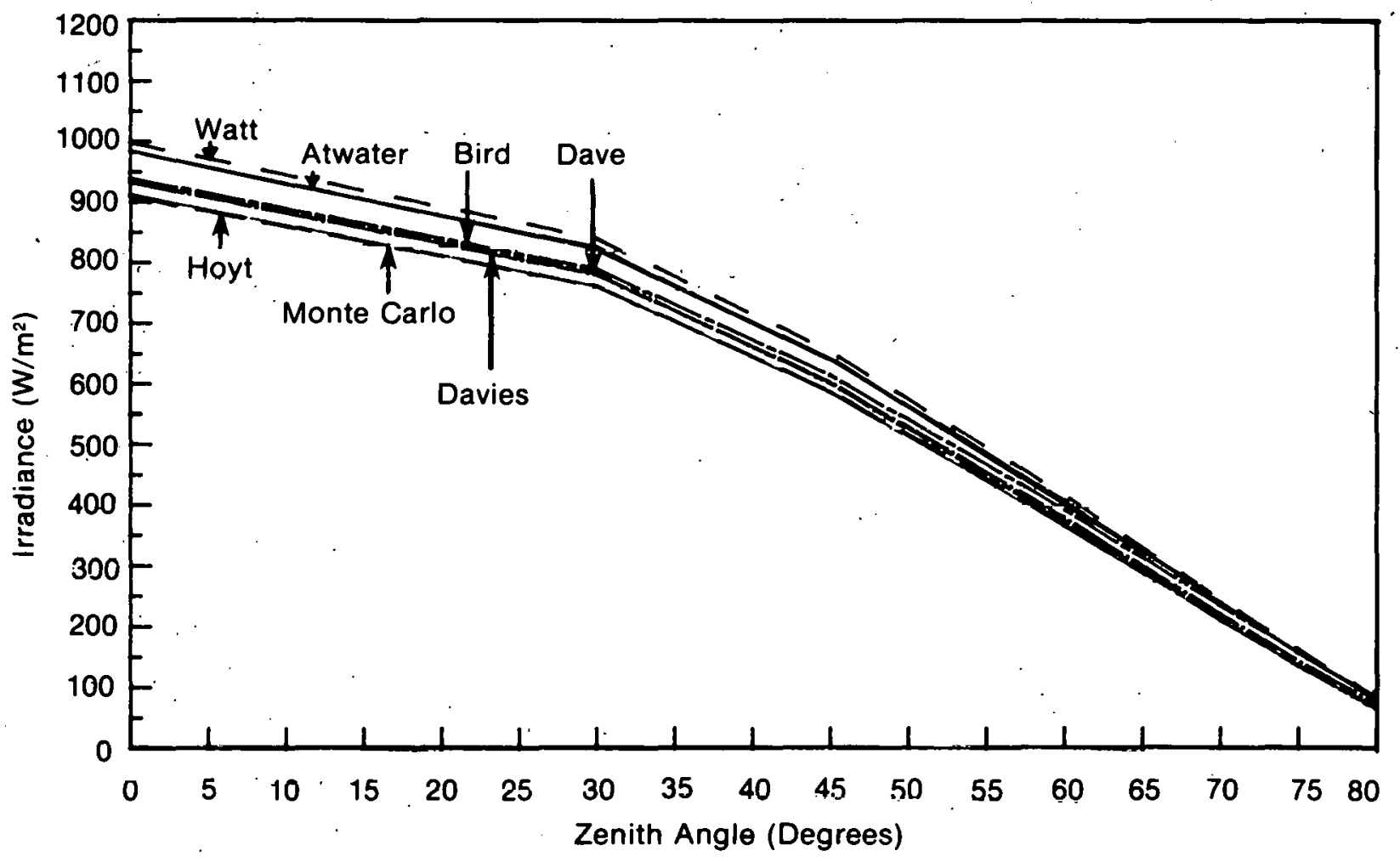

Figure 3-15. Direct Horizontal Insolation-Dave Model 3 $\left(U_{W}=2.93 \mathrm{~cm}, U_{0}=0.31 \mathrm{~cm}\right)$ 


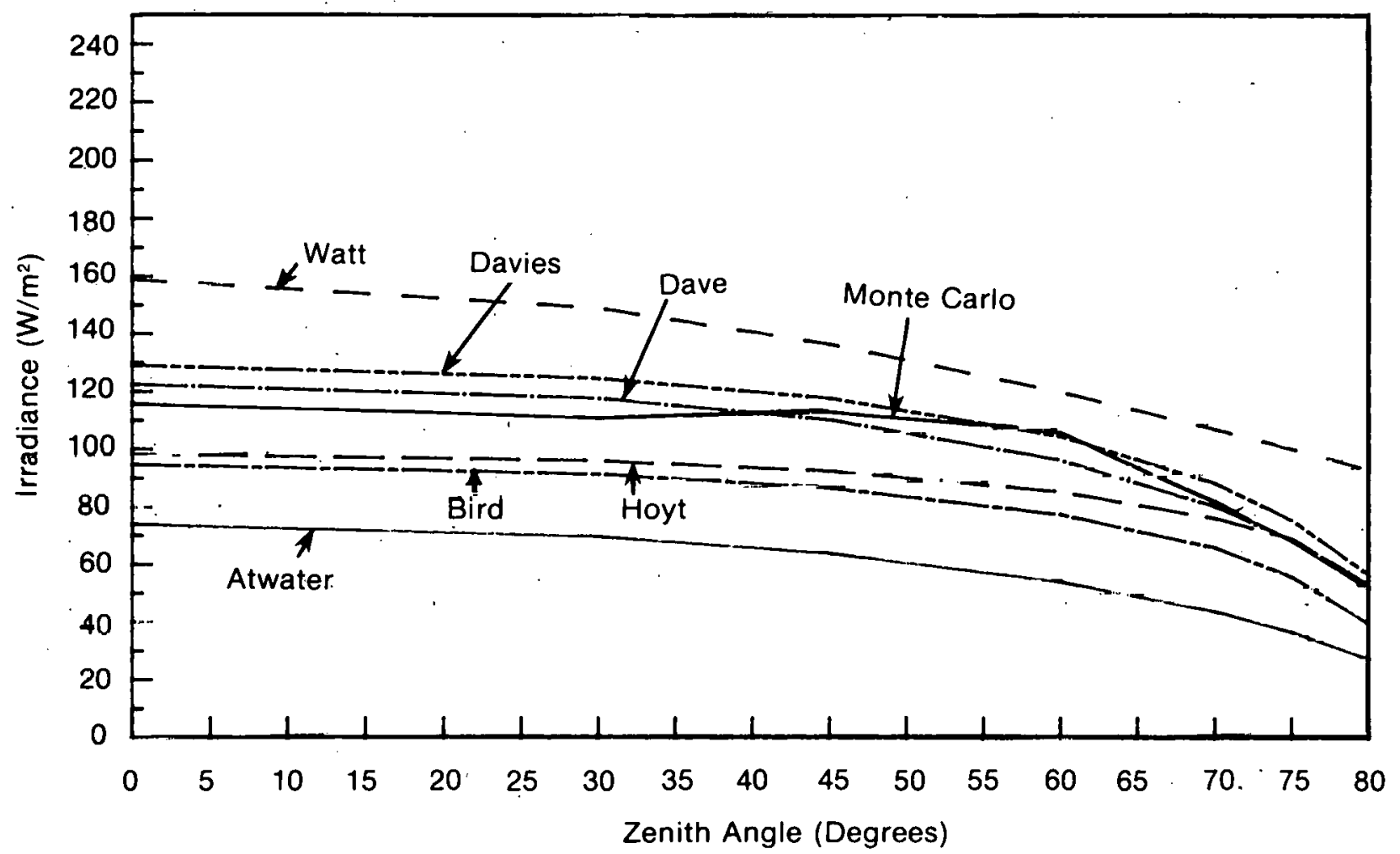

Figure 3-16. Diffuse Sky Insolation-Dave Model 3 $\left(U_{w}=2.93 \mathrm{~cm}, U_{0}=0.31 \mathrm{~cm}\right)$

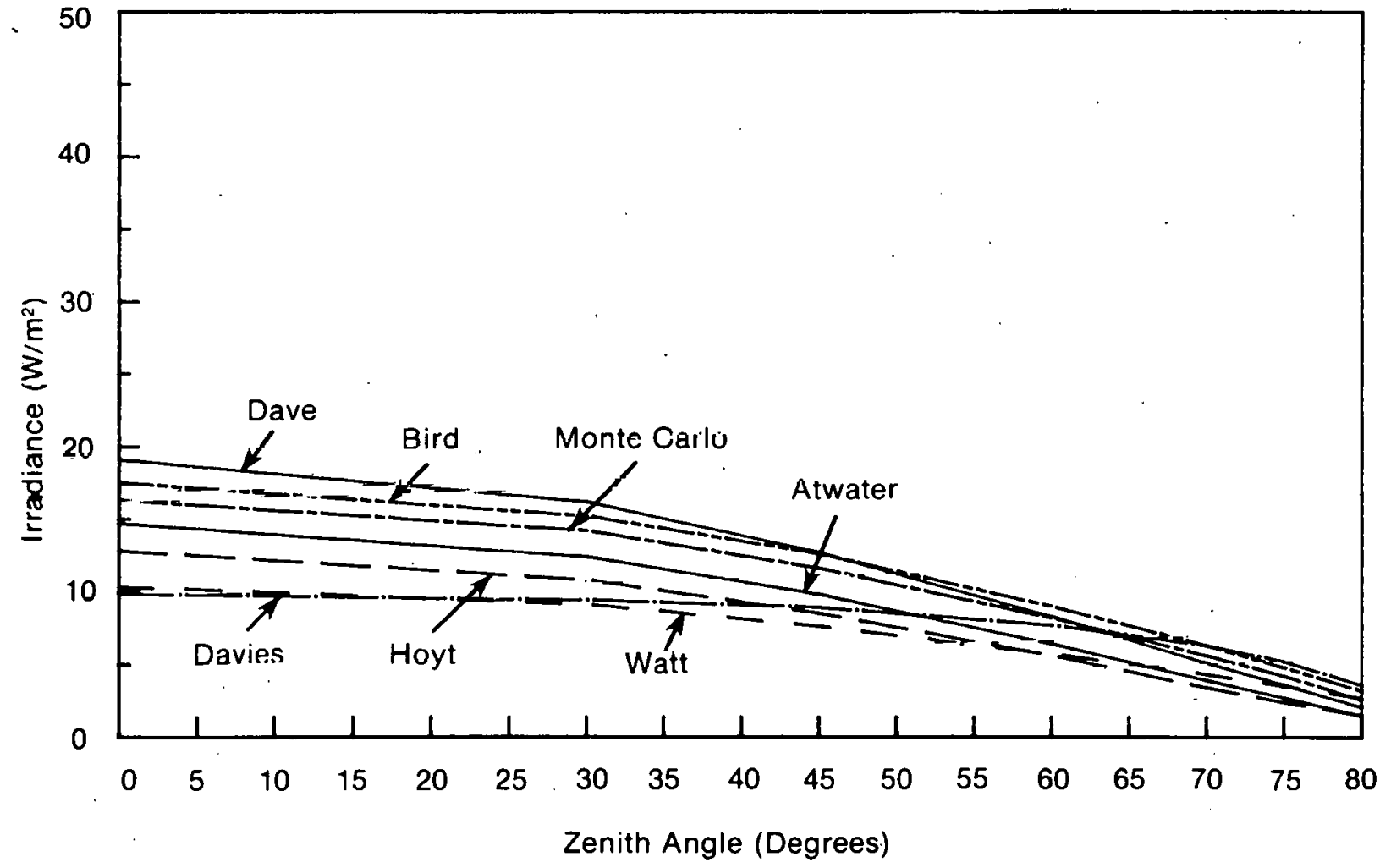

Figure 3-17. Diffuse Ground/Sky Insolation-Dave Model 3 (Albedo $=0.2)$ 
of molecular absorption coefficients from AFGL than was used in the Monte Carlo code [20]. Figure 3-18 is a comparison of the spectral direct irradiance for these two codes. It is evident that there are some weak absorption bands present in the Monte Carlo code that are not present in the spherical harmonics code, and the shape of some of the bands is significantly different for the two codes. SOLTRAN 4 is based on the same absorption data that Dave used, and similar differences in the direct normal irradiance occur between SOLTRAN 4 and the Monte Carlo code. These differences are shown in Fig. 3-19, which has 31 more data points in the Monte Carlo results than in Fig. 3-18. This increase in the number of data points increases the apparent spectral resolution. The SOLTRAN 4 code provided approximately 600 data points in this figure. Our conclusion is that most of the differences in the results from the rigorous codes are due to differences in the molecular absorption coefficients used.

A final observation is that many of the simple models have been based on actual measured data rather than comparison to rigorous models. This fact can make a difference in the direct normal irradiance or the diffuse irradiance but should not affect the total irradiance. The reason for this is that pyrheliometers measure the irradiance in a 5.8-degree field-of-view, which includes some diffuse or circumsolar irradiance. The rigorous codes include only the direct normal irradiance with no circumsolar. Th1s means that the direct normal irradiance calculated with the Bird model will slightly underestimale the irradiance measured by a pyrheliometer. On a normal clear day, one is talking about less than a $1 \%$ underestimation. Let us reiterate that the total insolation should agree. 


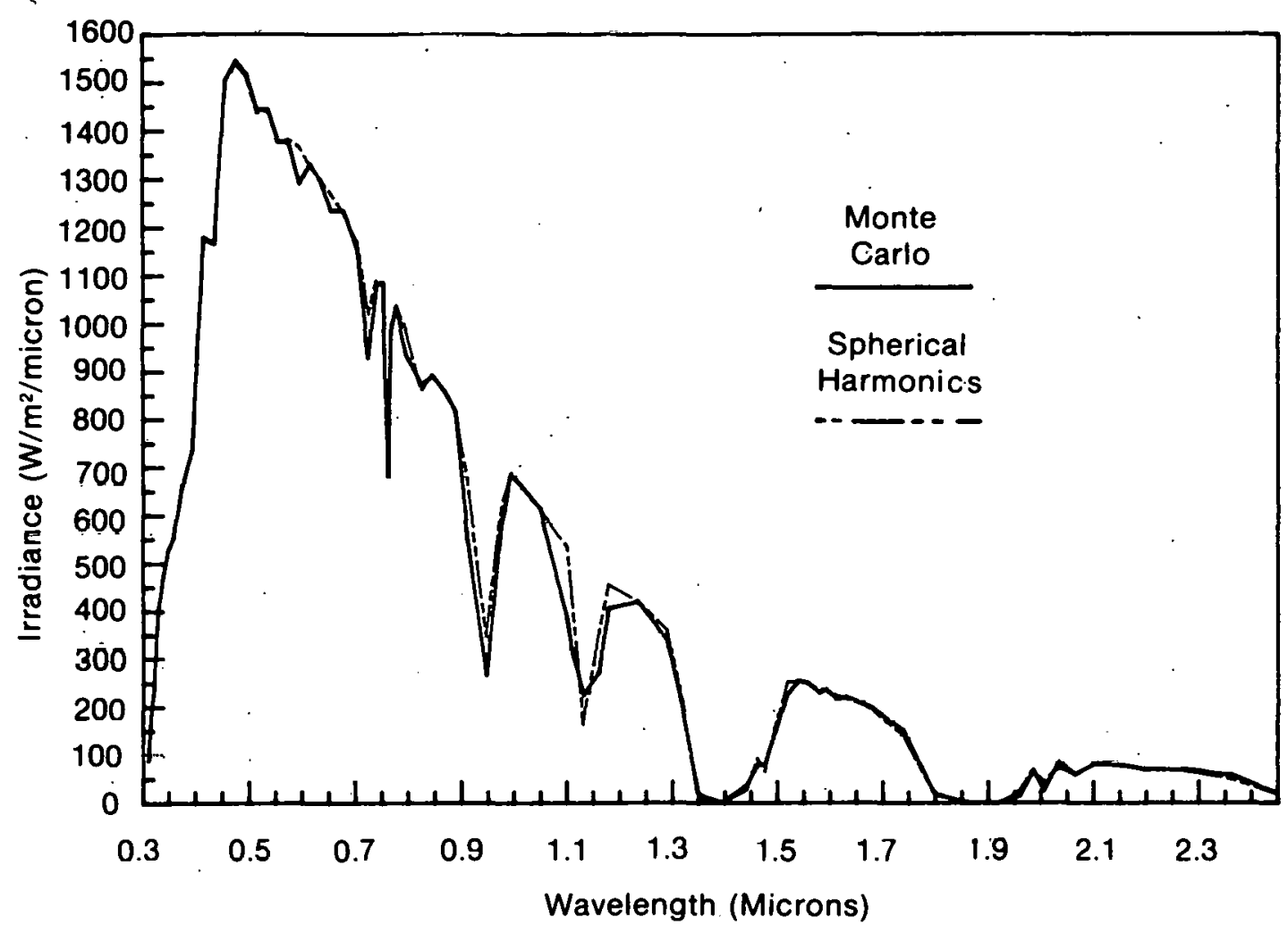

Figure 3-18. Direct Normal Insolation - Dave Model 3 (AM1.)

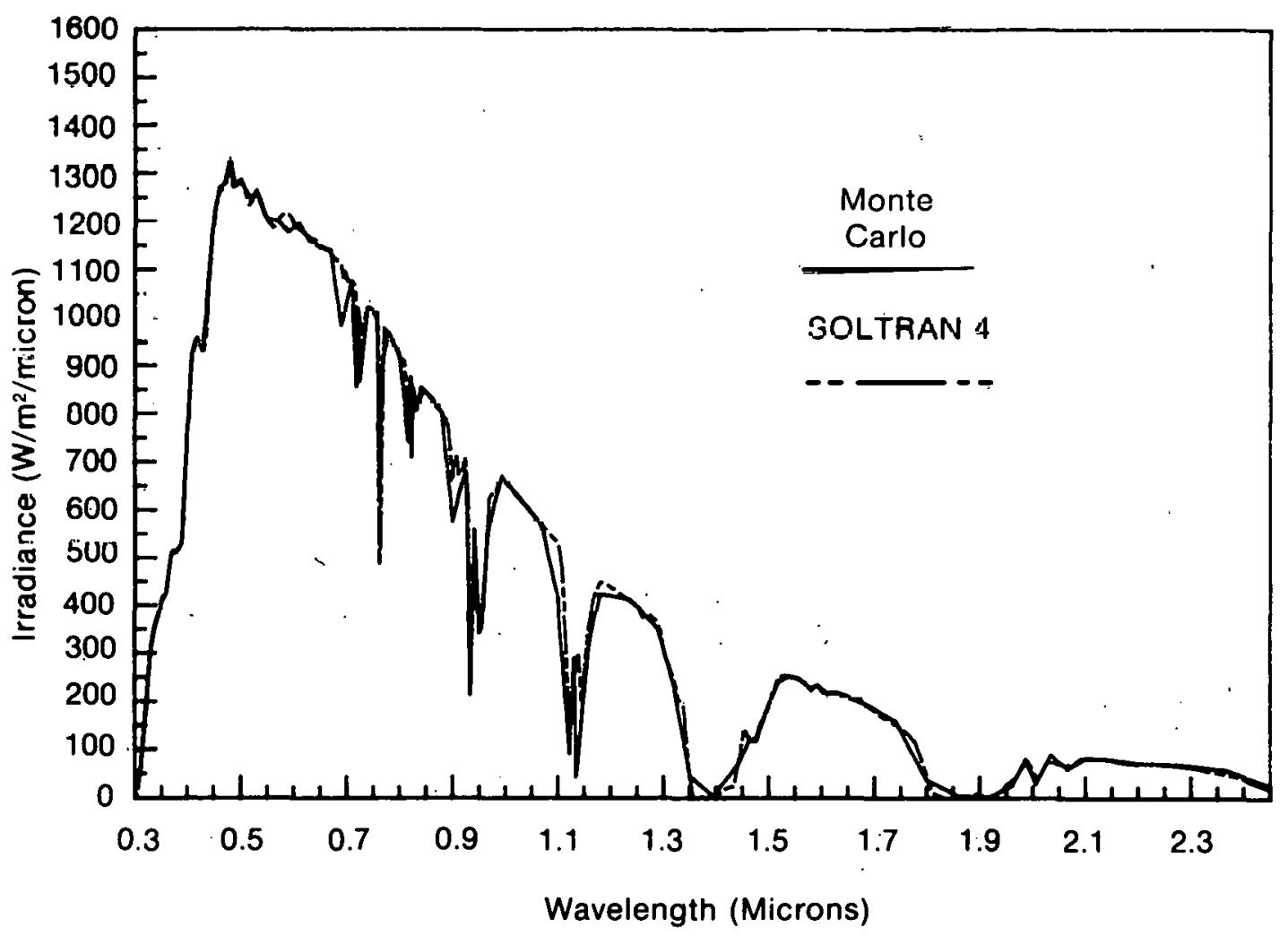

Figure 3-19. Direct Normal Insolation-USS Atmosphere (23-km-Visibility Rural Aerosol, AM1) 


\section{SUMMARY AND CONCLUSIONS}

Five simple broadband models for clear sky global horizontal insolation have been compared with the spectrally integrated results from three rigorous spectral codes. As a part of this comparison, a sixth simple broadband model has been formulated. This sixth model, designated the Bird model, uses parts of the formalisms from the other simple models and has been fine-tuned to provide good agreement with the rigorous codes. The Bird model was constructed so that readily available meteorological data could be used in it. It is based entirely on algebraic expressions rather than look-up tables, which greatly simplifies the use of the model.

The comparison of the results from each of the simple models with the results of the rigorous codes indicates the following:

- The Atwater and Ball model is applicable to extremely clear atmospheric conditions with an atmospheric turbidity (base e) near $0.1-$ at $0.5-\mu \mathrm{m}$ wavelength. For turbidities near 0.27 , this model underestimated the global irradiance by approximately $8 \%$ for air mass 1 (AM1). This model is extremely simple but does not have a good method of treating aerosol transmittance.

- The Watt model is relatively complicated and appears to overestimate the global insolation for AMl conditions by approximately $7 \%$. This is a complete model based on meteorological parameters. However, the upper air turbidity required in this model is not readily available.

- The Hoyt model provides excellent agreement with the rigorous codes. However, its use of look-up tables and the requirement to recalculate transmittance and absorptance parameters for modifled air mass values causes this model to be relatively difficult to use.

- The Lacis and Hansen model is extremely simple. It tends to overestimate the global irradiance by approximately $8 \%$ at AMl, and it has no provisions for calculating direct irradiance.

- The Davies and Hay model could possibly provide good agreement with the rigorous codes. However, it uses a look-up table for the Rayleigh scattering transmittance term and does not have a good method for treating aerosol transmittance. The aerosol transmittance through a vertical path used by Davies and Hay for southern Ontario $(\mathrm{K}=0.91)$ is for an extremely clear atmosphere.

- It is hoped that the rigorous codes and accurate simple models will provide results that will agree within $\pm 5 \%$ with quality experimental data on clear days. Cloudy days are much more difficult to model accurately, and clouds can have the greatest effect on the total irradiance. Models that address cloud influences for irradiance will be examined at a later date. 
- It should be recalled that the basis of comparison/evaluation of the simple models is the much more rigorous radiative transfer codes--as opposed to a comparison with actual data. Because of a lack of sultable, high-quality data, comparisons with actual data are impossible at this time. The greatest deficiency has been the lack of meteorological measurements accompanying good insolation data. However, efforts* are currently underway at SERI and several universities to provide such data. As this data becomes available, comparisons and improvements will be made. Until then, it appears that both the Hoyt and Bird simplified models yield results in good agreement with the rigorous techniques. However, the Bird model is more flexible and easily used.

* As part of the U.S. Department of Energy's Insolation Resource Assessment Program. 
SECTION 5.0

\section{REFERENCES}

1. Moon, P. "Proposed Standard Solar-Radiation Curves for Engineering Use." J. Franklin Institute. Vol. 230: pp. 583-617; 1940.

2. Mahaptra, A. K. "An Evaluation of a Spectroradiometer for the VisibleUltraviolet and Near-U1traviolet." Ph.D. dissertation; University of Missouri; Columbia, Mo; 1973; 121 pp. (University Microfilms 74-9964).

3. Watt, D. On the Nature and Distribution of Solar Radiation. HCP/T2552-01. U.S. Department of Energy; 1978:

4. Bird, R. E.; Hulstrom, R. E. Direct Insolation Models. SERI/TR-335-344. Golden, CO: Solar Energy Research Institute; 1980.

5. Davies, J. A.; Hay, J. E. "Calculation of the Solar Radiation Incident on a Horizontal Surface." Proceedings, First Canadian Solar Radiation Data Workshop. April 17-19, 1978. Canadian Atmospheric Environment Service; 1979.

6. Atwater, M. A.; Ba11, J. T. "A Numerical Solar Radiation Model Based on Standard Meteorological Observations." Solar Energy. Vol. 21: pp. 163-170; 1978.

7. Atwater, M. A.; Ba11, J. T. Solar Energy. Vo1. 23: p. 275; 1979.

8. Kondratyev, K. Ya. Radiation in the Atmosphere. New York: Academic Press; 1969.

9. McDonald, J. E. "Direct Absorption of Solar Radiation by Atmospheric Water Vapor." J. Meteorology. Vol. 17: pp. 319-328; 1960.

10. Lacis, A. L.; Hansen, .T. E. "A Parameterization for Absorption of Solar Radiation in the Earth's Atmosphere." J. Atmospheric Sclence. Vo1. 31: pp. 118-133; 1974.

11. Hoyt, D. V. "A Model for the Calculation of Solar Global Insolation." Solar Energy. Vol. 21: pp. 27-35; 1978.

12. Bemporad, A. Zur Theorie der Ext1nktion des Lichtes in der Erdatmosphare. Mitteilungen der Grossherzoglichen Sternmwarte Zu Heidelberg; No. 4; 1901.

13. Kasten, F. A New Table and Approximation Formula for the Relative Optical Air Mass. Technical Report 136. Hanover, New Hampshire: U.S. Army Material Command, Cold Region Research and Engineering Laboratory; 1964.

14. Bird, R. E.; Hilstrom, R. L. Application of Monte Carlo Techniques to Insolation Characterization and Prediction. SERI/RR-36-306. Solar Energy Research Institute; Golden, CO; 1979. 
15. Flowers, E. C.; McCormick, G. A.; Kurfis, K. R. "Atmospheric Turbidity over the United States." J. Appl. Meteor. Vol. 8: pp. 955-962; 1969.

16. Shettle, E. P.; Fenn, R. W. "Models of the Atmospheric Aerosol and Their Optical Properties." Proceedings of AGARD Conference No. 183, Optical Propagation in the Atmosphere. pp. 2.1-2.16; Presented at the Electromagnetic Wave Propagation Panel Symposium, Lyngby, Denmark; 27-31 October 1975.

17. Dave, J. V. "Extensive Datasets of the Diffuse Radiation in Realistic Atmospheric Models with Aerosols and Common Absorbing Gases." Solar Energy. Vol. 21: pp. 361-369; 1978.

18. Van Heuklon, T. K.' "Fstimating Atmnsphẹic OBone for Jular Radiation Mude1s." Solar Energy. Vol. 22: pp. 63-68; 1979.

19. Hooper, F. C.; Brunger, A. P. "A Model for the Angular Distribution of Sky Radiance." Presented at the Joint ASME/AIChE 18th National Heat Transfer Conference. San Diego, CA; 6-8 August 1979.

20. Rothman, L. S. "Update of AFGL Atmospheric Absorption Line Parameters Compilation." Applied.Optics. Vol. 17: pp. 3517-3518; 1978. 
APPENDIX A

TABULATED MODEL DATA 
Three sets of tabulated data from each simple model are presented here, and each set represents one of the atmospheric models discussed in the main text. The parameters listed at the top of each table are:

$\mathrm{I}_{\mathrm{o}} \quad=$ Solar constant $\left(\mathrm{W} / \mathrm{m}^{2}\right)$

$\mathrm{UW}=$ Precipitable water vapor in vertical path $(\mathrm{cm})$

UO $=$ Ozone amount in vertical path $(\mathrm{cm})$

$\mathrm{PR} \quad=$ Surface pressure $(\mathrm{mb})$

TAU5 = Turbidity at $0.5-\mu \mathrm{m}$ wavelength

TAU38 = Turbidity at $0.38-\mu \mathrm{m}$ wavelength

RS $=$ Ground albedo

IEMP = Surface temperature $(K)$

CONST $=$ Constant $K$ used in BIRD model

$B \Lambda$ - Toiwald to cotal scattered irradiance ratio

TAUB $=$ Broadband turbidity

The parameters at the top of each column of data are self-explanatory for the transmittance and absorptance terms. The remaining parameters are:

DIRH $=$ Direct horizontal irradiance $\left(\mathrm{W} / \mathrm{m}^{2}\right)$

DIFSH $=$ Diffuse sky horizontal irradiance $\left(W / \mathrm{m}^{2}\right)$

DIFGI = Diffuse ground horizontal irradiance $\left(\mathrm{W} / \mathrm{m}^{2}\right)$

DTOT $=$ Total or global horizontal irradiance $\left(\mathrm{W} / \mathrm{m}^{2}\right)$ 
Table A-1. TABULATED DATA FROM SEVERAL MODELS FOR THE USS ATMOSPHERE

$\begin{array}{lr}\text { IO }= & 1353.0000 \\ \text { UW }= & 1.4200 \\ \text { UO }= & .3400 \\ \text { PR }= & 1013.0000 \\ \text { TAUS }= & .2661 \\ \text { TAU38 }= & .3538 \\ \text { RS }= & .2000 \\ \text { TEMP }= & 288.1000 \\ \text { CONST }= & .0933 \\ \text { BA }= & .8200 \\ \text { TAUB }= & .1907\end{array}$

$\begin{array}{rr}\text { ZENITH } & \text { AIRMASS } \\ 0.0000 & .9995 \\ 20.0000 & 1.0634 \\ 30.0000 & 1.1536 \\ 48.1900 & 1.4972 \\ 50.0000 & 1.5525 \\ 60.0000 & 1.9927 \\ 70.0000 & 2.8997 \\ 75.0000 & 3.8076 \\ 80.0000 & 5.5790 \\ 85.0000 & 10.3163\end{array}$

ATWATER MODEL

\begin{tabular}{rrrrrrrr} 
ZEN & TA & AW & TMD & DIRH & DIFSH & \multicolumn{1}{c}{ DIFEH } & DTOT \\
0.0 & .8264 & .0855 & .9381 & 888.2846 & 64.9349 & 13.2405 & 966.4600 \\
20.0 & .8163 & .0872 & .9355 & 917.4250 & 62.8348 & 12.2298 & 892.6897 \\
30.0 & .8024 & .0893 & .9319 & 732.1165 & 60.0704 & 11.0037 & 803.1906 \\
48.2 & .7513 & .0966 & .9195 & 506.4300 & 51.2334 & 7.7461 & 565.4095 \\
50.0 & .7434 & .0977 & .9176 & 480.1187 & 50.0130 & 7.3637 & 537.4954 \\
60.0 & .6832 & .1053 & .9038 & 327.3209 & 41.7589 & 5.1266 & 374.2064 \\
70.0 & .5736 & .1179 & .9795 & 172.0532 & 30.0717 & 2.8076 & 204.9324 \\
75.0 & .4806 & .1281 & .8585 & 100.5358 & 22.3903 & 1.7075 & 124.6335 \\
80.0 & .3382 & .1441 & .8233 & 40.7697 & 13.2023 & .7497 & 54.7216 \\
85.0 & .1249 & .1752 & .7472 & 4.9225 & 3.5038 & .1170 & 8.5433
\end{tabular}

WATT MODEL

\begin{tabular}{rccc|} 
ZEN & TA & TH2OA & TH2OS \\
0.0 & .8653 & .9250 & .9694 \\
20.0 & .8590 & .9241 & .9675 \\
30.0 & .8503 & .9229 & .9648 \\
48.2 & .8187 & .9192 & .9545 \\
50.0 & .8138 & .9186 & .9528 \\
60.0 & .7770 & .9150 & .9398 \\
70.0 & .7092 & .9096 & .9132 \\
75.0 & .6544 & .9056 & .8873 \\
80.0 & .5620 & .9000 & .8373 \\
85.0 & .3961 & .9904 & .7074
\end{tabular}

703
.9761
.9756
.9749
.9723
.9719
.9685
.9615
.9562
.9456
.9254

TAIR
.9016
.8974
.8917
.8714
.8683
.8451
.8029
.7702
.7142

DIRH 923.885 176.483 Q94.898 171.361 $771.205 \quad 165.065$ $548.932 \quad 147.788$ $522.831 \quad 145.694$ $369.969 \quad 133.040$ $210.444 \quad 118.758$ $135,596 \quad 111,100$ $\begin{array}{lll}7142 & 67.205 & 103.151\end{array}$ 1170

HOYT MODEL

$\begin{array}{cccc}\text { ZEN } & \text { TAS } & \text { AA } & \text { AH } \\ 0.0 & .8317 & .0416 & .100 \\ 20.0 & .8220 & .0411 & .1021 \\ 30.0 & .8084 & .0404 & .1049 \\ 48.2 & .7598 & .0379 & .1144 \\ 50.0 & .7911 & .0376 & .1158 \\ 60.0 & .6926 & .0346 & .1258 \\ 70.0 & .5859 & .0293 & .1422 \\ 75.0 & .4956 & .0248 & .1553\end{array}$

ZEN DIRH

$\begin{array}{rr}\text { ZEN } & \text { DIRH } \\ 0.0 & 842.7127 \\ 20.0 & 776.0245 \\ 30.0 & 695.2566 \\ 48.2 & 482.1123 \\ 50.0 & 457.2772 \\ 60.0 & 313.2352 \\ 70.0 & 167.1730 \\ 75.0 & 99.6955\end{array}$

DIFSH

185.2787

183. 3879

171.6728

170.2822

159.8604

111.5303

AH
1000
1021
1049
1144
1158
1258
1422
1553

ACO2
.0075
.0076
.0078
.0084
.0085
.0091
.0101
.0109

A03

.0268

.0285

0317

0322

.0357

.0466

DIFGH DTOT

11.272 1111:639

$10.680 \quad 1036.929$

9.957946 .227

$7.996 \quad 704.717$

$7.761 \quad 676.286$

6.352 509.361

4.789333 .991

$3.963 \quad 333.991$

3.963250 .659

$\begin{array}{ll}3.117 & 173.473 \\ 2.255 & 113.888\end{array}$

75.0

99.6955

126.4744

DIFGH
19.8473
18.4825
16.8257
12.4167
11.8978
8.8494
5.6278
4.0258

DTOT

1047.8387

977.8849

892.8972

666.2018
639.4573

639.4573
481.9533

314.3311

230.1957 
Table A-1. TABULATED DATA FROM SEVERAL MODELS FOR THE USS ATMOSPHERE (concluded)

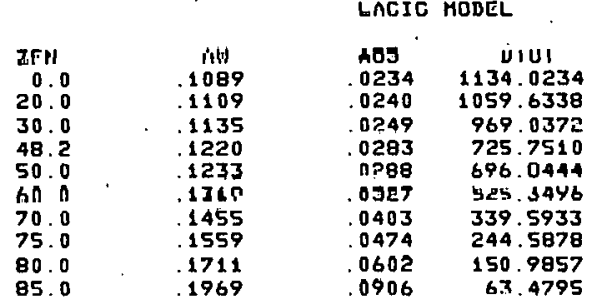

DAVIES MODEL

$\begin{array}{rr}\text { ZEN } & \text { DIRH } \\ 0.0 & 964.6041 \\ 20.0 & 893.1822 \\ 30.0 & 806.4406 \\ 48.2 & 575.4248 \\ 50.0 & 548.2303 \\ 60.0 & 388.6384 \\ 70.0 & 221.5297 \\ 75.0 & 140.6761 \\ 80.0 & 68.5779 \\ 85.0 & 16.1786\end{array}$

DIFSH
131.3193
129.3610
126.7305
117.7340
116.4077
106.7716
90.5812
77.6703
58.6164
29.9684

DIFGH
18.2102
17.1608
15.9783
12.3977
11.9791
9.4598
6.6085
5.0465
3.7589
1.5249

DTOT 1114.1335 949.0494 705.5564 676.6171 504.8698 504.8698
318.7193 319.7193
223.5929 130.5535
47.6719

BIRD MODEL

$\begin{array}{ccc}\text { ZEN } & \text { TA } & \text { TOJ } \\ 0.0 & .8127 & .482 \\ 20 . Q & .8029 & .981 \\ 30.0 & .7695 & .960 \\ 48.2 & .7410 & .976 \\ 50.0 & .7336 & .975 \\ 60.0 & .6778 & .970 \\ 70.0 & .5785 & .961 \\ 75.0 & .4959 & .953 \\ 80.0 & .3704 & .939 \\ 85.0 & .1757 & .905\end{array}$

$\begin{array}{ccccc}\text { riU } & \text { TR } & \text { TAS } & \text { AH } & \text { TAH } \\ .9874 & .9137 & .8271 & .1032 & .9825 \\ .9872 & 9094 & .9100 & .1046 & .9826 \\ .9869 & .9033 & .8055 & .1068 & .9801 \\ 9880 & .9816 & .7603 & .1134 & .9746 \\ .9859 & .9783 & .7541 & .1144 & .9728 \\ .9849 & .8531 & .7029 & .1209 & .9643 \\ .9834 & .8074 & .6126 & .1312 & .9444 \\ .9822 & .7684 & .5435 & .1389 & .9124 \\ .9803 & .7078 & .4494 & .1499 & .9242 \\ 9770 & 6157 & .256 & 1684 & 4130\end{array}$

\begin{tabular}{|c|c|c|c|c|}
\hline $\begin{array}{l}\text { ZEN } \\
0.0 \\
20.0 \\
30.0 \\
48.2 \\
50.0 \\
60.0 \\
70.0 \\
75.0 \\
80.0 \\
85.0\end{array}$ & $\begin{array}{r}\text { DIRH } \\
\text { B44.2037 } \\
777.9391 \\
697.7136 \\
485.8908 \\
461.1879 \\
317.6805 \\
171.6204 \\
103.9953 \\
46.5685 \\
9.0703\end{array}$ & $\begin{array}{l}\text { DIFSH } \\
168.9023 \\
166.1341 \\
162.3802 \\
149.7404 \\
147.4321 \\
133.6742 \\
1115682 \\
90.4421 \\
59.8652 \\
12.5752\end{array}$ & $\begin{array}{r}\text { DIFGH } \\
20.5954 \\
19.5137 \\
19.1816 \\
14.5168 \\
14.0423 \\
11.2868 \\
0.0537 \\
6.0411 \\
3.6917 \\
.7707\end{array}$ & $\begin{array}{c}\text { DTOT } \\
1033.7014 \\
963.5869 \\
878.2754 \\
650.1480 \\
622.6523 \\
462.6415 \\
740.4114 \\
200.4786 \\
110.1254 \\
22.4162\end{array}$ \\
\hline
\end{tabular}


Table A-2. TABULATED DATA FROM SEVERAL MODELS FOR THE MLS ATMOSPHERE

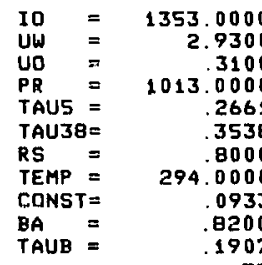

$\begin{array}{rr}\text { ZENITH } & \text { AIRMASS } \\ 0.0000 & .9995 \\ 20.0000 & 1.0634 \\ 30.0000 & 1.1536 \\ 48.1900 & 1.4972 \\ 50.0000 & 1.5525 \\ 60.0000 & 1.9927 \\ 70.0000 & 2.8997 \\ 75.0000 & 3.8076 \\ 80.0000 & 5.5790 \\ 85.0000 & 10.3163\end{array}$

ATWATER MODEL

$\begin{array}{cc}\text { ZEN } & \text { TA } \\ \text { N } 0 & .8264 \\ 20.0 & .8163 \\ 30.0 & .802 \\ 48.2 & .7513 \\ 50.0 & .7434 \\ 60.0 & .6832 \\ 70.0 & .5736 \\ 75.0 & .4806 \\ 80.0 & .338 \\ 85.0 & .1249\end{array}$

\begin{tabular}{ccc} 
AW & TMD & \multicolumn{1}{c}{ DIRH } \\
.1063 & .9381 & 865.0702 \\
1083 & .9355 & 795.6702 \\
1110 & .9319 & 711.7362 \\
.1200 & .9195 & 490.5418 \\
1214 & .9176 & 464.7946 \\
1308 & .9038 & 315.5108 \\
1465 & .8795 & 164.4570 \\
11592 & .8585 & 95.3030 \\
1790 & .8233 & 37.9910 \\
.2177 & .7472 & 4.2961
\end{tabular}

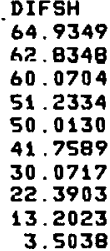

DIFGH DTOT

$53.9190 \quad 983.9241$

49.7737908 .278

44.7471816 .5539

31.4106573 .1858

$29.8471 \quad 544.6547$

$20.7135 \quad 377.9832$

$11.2782 \quad 205.8069$

$6.8235 \quad 124.5168$

2. $9680 \quad 54.1614$

WATT MODEL

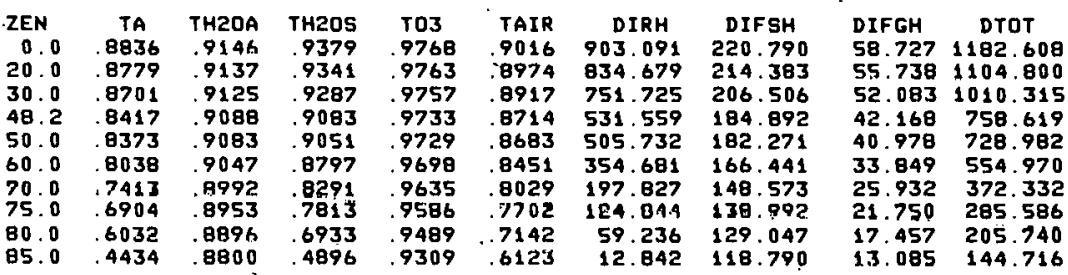

- HOYT MODEL

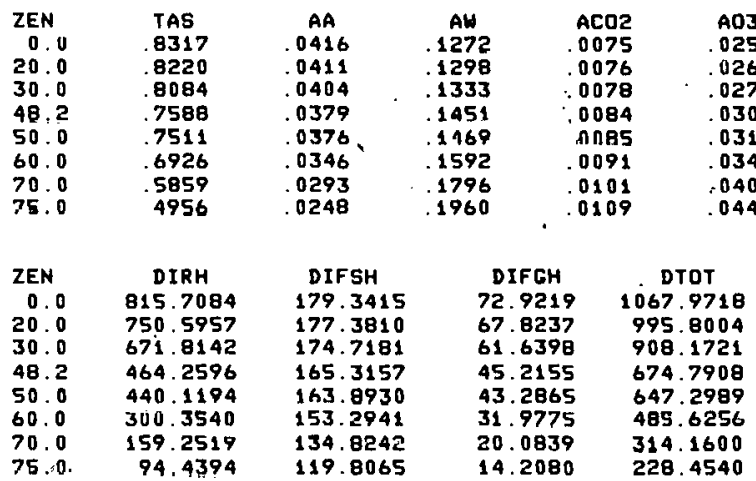


Table A-2. TABULATED DATA FROM SEVERAL MODELS FOR THE MLS $\Lambda$ TMOSPHERE (concluded)

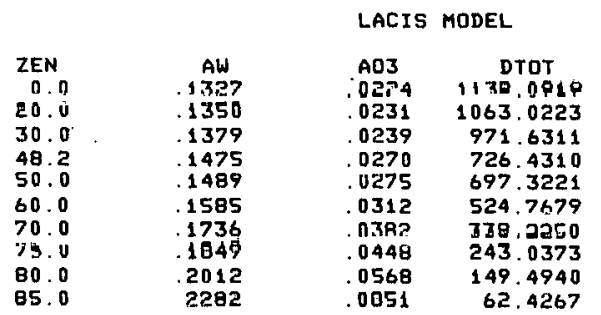

DAUIES MODEL

$\begin{array}{rr}\text { ZEN } & \text { DIRH } \\ 0.0 & 936.3331 \\ 20.0 & 866.5097 \\ 30.0 & 781.7525 \\ 48.2 & 556.3066 \\ 50.0 & 529.8009 \\ 60.0 & 374.4382 \\ 70.0 & 212.2479 \\ 75.0 & 134.2798 \\ 80.0 & 64.7464 \\ 85.0 & 14.9323\end{array}$

DIFSH

129.0411

27.0680

124.4193

115. 3767

1.14 .0456
104.3899

98. 2198

$-75.3692$

56.4768

28.3066

BIRD MODEL.

DIFGH

74.5253

70.2349

64.9933

50.7790

49.0708

38.7949

27.1739

20.0053

13.9067

6. 3442

DTOT

1139.8995

971.1651

722.4623

692.9173

517.6231

327.6415

230.4543

135.1298

$\begin{array}{cc}\text { ZEN } & \text { TA } \\ 0.0 & .8127 \\ 20.0 & .81179 \\ 30.0 & .7895 \\ 48.2 & .7410 \\ 50.0 & .7336 \\ 60.0 & .6778 \\ 70.0 & .5785 \\ 75.0 & .4959 \\ 80.0 & .3704 \\ 85.0 & .1757 \\ & \\ Z E N & \\ 0.0 & 827.6234 \\ 20.0 & 762.5502 \\ 30.0 & 603.7850 \\ 18.2 & 475.9279 \\ 50.0 & 451.6994 \\ 60.0 & 311.0063 \\ 70.0 & 167.9332 \\ 75.0 & 101.7433 \\ 00.0 & 45.6637 \\ 85.0 & 8.8855 \\ & \\ & \end{array}$

TO3

.9834

.9836
.9816

9778

.9772

.9727

9643

9566

.9430

$T U$
987
.707
.986
.9860
.985
.984
.983
.982
.9803
.9770

TR
.5137
.9044
.9033
.0916
.8783
.8531
.8074
.7684
.7078
.6157

TAS

.817

.8055

.7603

.7541

.6126

.4494
.4256

$\begin{array}{cc}\text { AH } & \text { TAA } \\ 1219 & .9925 \\ .1235 & .9815 \\ .1257 & .9801 \\ .1330 & .9746 \\ .1340 & .9728 \\ .1411 & .9643 \\ .1520 & .9444 \\ .1601 & .9124 \\ .1717 & .8242 \\ .1907 & .4130\end{array}$

DIFSH

165.5850

162.8477

159.1305

146.6700

144.3891

130.8658

108.1927

88. 4834

58.3735
12.3191

DIFGH

$\begin{array}{ll}86.0091 & 1079.2176 \\ 81.5689 & 1006.9669\end{array}$

DTDT

$76.10117 \quad 019.0343$

$61.0603 \quad 683.6593$

$59.1048 \quad 655.1932$

59.1048 655.1932

$47.7834 \quad 489.6554$

$26 . n 710 \quad 216.8770$

$\begin{array}{rr}16.1263 & 120.2635 \\ 3.3810 & 24.5857\end{array}$ 
Table A-3. TABULATED DATA FROM SEVERAL MODELS FOR THE DAVE MODEL 3 ATMOSPHERE

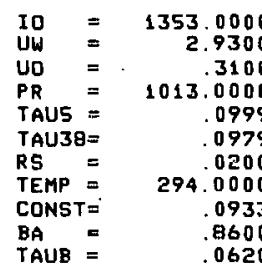

$\begin{array}{rr}\text { ZENITH } & \text { AIRMASS } \\ 0.0000 & .9995 \\ 20.0000 & 1.0634 \\ 30.0000 & 1.1536 \\ 48.1900 & 1.4972 \\ 50.0000 & 1.5525 \\ 60.0000 & 1.9927 \\ 70.0000 & 2.8997 \\ 75.0000 & 3.8076 \\ 80.0000 & 5.5790 \\ 95.0000 & 10.3163\end{array}$

ATHATER MODEL

$\begin{array}{rr}\text { ZEN } & \text { TA } \\ 0.0 & .9399 \\ 20.0 & .9362 \\ 30.0 & .9310 \\ 48.2 & .9113 \\ 50.0 & .908 \\ 60.0 & .8836 \\ 70.0 & .8348 \\ 75.0 & .7881 \\ 80.0 & .7031 \\ 85.0 & .5087\end{array}$

\begin{tabular}{ccc} 
AW & TMD & \multicolumn{1}{c}{ DIRH } \\
.1063 & .9381 & 983.9331 \\
.1083 & .9355 & 912.4993 \\
.1110 & .9319 & 825.7991 \\
.1200 & .9195 & 594.9837 \\
.1214 & .9176 & 567.8031 \\
.1308 & .9038 & 408.0431 \\
.1465 & .8795 & 239.3498 \\
.1592 & .8585 & 156.2876 \\
1790 & .8233 & 78.9828 \\
.2177 & .7472 & 17.4954
\end{tabular}
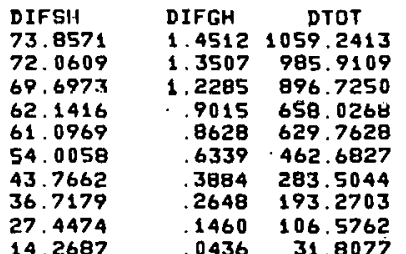

WATT MODEL

$\begin{array}{cccc}\text { ZEN } & \text { TA } & \text { TH20A } & \text { TH20 } \\ \text { Y0.0 } & .9762 & .9146 & .937 \\ 20.0 & .9743 & .9137 & .934 \\ 30.0 & .9716 & .9125 & .928 \\ 48.2 & .9609 & .9088 & .908 \\ 50.0 & .9592 & .9083 & .905 \\ 60.0 & .9452 & .9047 & .879 \\ 70.0 & .9157 & .8992 & .829 \\ 75.0 & .8921 & .8953 & 781 \\ 80.0 & .8457 & .8896 & .693 \\ 85.0 & .7602 & .8800 & .4896\end{array}$

Th3

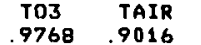

DIRH

DIFSH

$.9768 \quad .9016 \quad 997.790 \quad 158.878$

$.9763 \quad .8974 \quad .926 .307 \cdot 154.267$

$\begin{array}{llll}.9757 & .8917 & 839.372 & 148.600\end{array}$

$\begin{array}{llll}.9733 & .8714 \quad 606.839 & 133.046\end{array}$

$\begin{array}{llll}.9729 & .8683 & 579.335 & 131.160\end{array}$

$\begin{array}{llll}.9698 & .8451 & 417.053 & 119.769\end{array}$

$\begin{array}{llll}.9635 & .8029 & 244.378 & 106.911\end{array}$

$9586 \quad 7702 \quad 161.311 \quad 100.017$

$.9489 \quad 7142 \quad 83.046 \quad 32.064$

$\begin{array}{llll}.9309 & .7142 & 83.046 & 92.061 \\ & .623 & 22.017 & 85.480\end{array}$

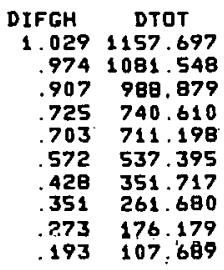

HOYT MODEL

$\begin{array}{cccccccc}\text { ZEN } & \text { TAS } & \text { AA } & \text { AW } & \text { ACO2 } & \text { A03 } & \text { A02 } & \text { TR } \\ 0.0 & .9321 & .0466 & .1272 & .0075 & .0258 & .0075 & .9170 \\ 20.0 & .9279 & .0464 & .1298 & .0076 & .0264 & .0079 & .9125 \\ 30.0 & .9220 & .0461 & .1333 & .0078 & .0274 & .0085 & .0063 \\ 48.2 & .9000 & .0450 & .1451 & .0084 & .0305 & .0107 & .8840 \\ 50.0 & .0965 & .0448 & .1469 & .0085 & .0310 & .0110 & .8907 \\ 60.0 & .8692 & .0435 & .1592 & .0091 & 0344 & .0137 & .8560 \\ 70.0 & .8155 & .0408 & .1796 & .0101 & .0401 & .0190 & .0138 \\ 75.0 & .7650 & .0383 & .1960 & .0109 & .0448 & .0242 & .7781\end{array}$

$\begin{array}{rcllr}\text { ZEN } & \text { DIRH } & \text { DIFSH } & \text { DIFGH } & \text { DTOT } \\ 0.0 & 908.3464 & 98.2025 & 1.2750 & 1007.8240 \\ 20.0 & 841.6283 & 97.2154 & 1.1857 & 940.0295 \\ 30.0 & 760.6718 & 95.8785 & 1.0773 & 857.6276 \\ 48.2 & 545.5922 & 91.1694 & .7889 & 637.5504 \\ 50.0 & 520.3379 & 90.4580 & .7548 & 611.5508 \\ 60.0 & 372.5084 & 85.1641 & .5554 & 458.2279 \\ 70.0 & 218.1138 & 76.0972 & .3449 & 294.5559 \\ 75.0 & 142.9609 & 68.9767 & .2407 & 212.1792\end{array}$


Table A-3. TABULATED DATA FROM SEVERAL MODELS FOR THE DAVE MODEL 3 ATMOSPHERE (concluded)

\begin{tabular}{cccc} 
& \multicolumn{2}{l}{ LACIS MODEL } \\
ZEN & AW & AO3 & DTOT \\
0.0 & .1327 & .0224 & 1093.1443 \\
20.0 & .1350 & .0231 & 1020.9793 \\
30.0 & .1379 & .0239 & 933.1311 \\
48.2 & .1475 & .0270 & 697.4799 \\
50.0 & .1489 & 0275 & 469.5094 \\
60.0 & .1585 & .0312 & 503.7295 \\
70.0 & .1736 & .0382 & 324.5709 \\
75.0 & .1849 & .0448 & 233.1836 \\
80.0 & .2012 & .0568 & 143.4038 \\
85.0 & .2282 & .0851 & 59.8739
\end{tabular}

DAUIES MODEL

$\begin{array}{rr}\text { ZEH } & \text { DIRH } \\ 0.0 & 936.3331 \\ 20.0 & 866.5097 \\ 30.0 & 781.7525 \\ 48.2 & 556.3066 \\ 50.0 & 529.8009 \\ 60.0 & 374.4382 \\ 70.0 & 212.2479 \\ 75.0 & 134.2798 \\ 80.0 & 64.7464 \\ 85.0 & 14.9323\end{array}$

U1FSH
129.0411
127.0680
124.4193
115.3767
114.0456
104.3899
88.2198
75.3692
56.4768
28.3066

\begin{tabular}{lr} 
DIFGH & \multicolumn{1}{c}{ DTOT } \\
1.7442 & 1067.1183 \\
1.6427 & 995.2204 \\
1.5186 & 907.6905 \\
1.1823 & 672.8657 \\
1.2419 & 644.9885 \\
.8989 & 479.7270 \\
.6243 & 301.0919 \\
.4742 & 210.1237 \\
.3127 & 121.5359 \\
11388 & 43.3777
\end{tabular}

RIRD MODEL

$\begin{array}{cc}\angle 5 N & \text { TO } \\ 0.0 & .9219 \\ 20.0 & .9175 \\ 30.0 & .9115 \\ 48.2 & .0091 \\ 50.0 & .9856 \\ 60.0 & .8585 \\ 70.0 & .8068 \\ 75.0 & 7595 \\ 80.0 & .6774 \\ 85.0 & .5057\end{array}$

$\begin{array}{ll}T 03 & 7 U \\ .9834 & .9874 \\ .9826 & .9872 \\ .9816 & .9869 \\ .9778 & .9860 \\ .97 \% 2 & .9859 \\ .9727 & .9849 \\ .9643 & .9834 \\ .9566 & .9822 \\ 9471 & .9003 \\ .9116 & .9770\end{array}$

$\begin{array}{cc}\text { TR } & \text { TAS } \\ .9137 & .9286 \\ .9094 & .9247 \\ .9033 & .9192 \\ .8816 & .9989 \\ .8793 & .8961 \\ .0531 & .8722 \\ .8074 & .8279 \\ .1644 & .7926 \\ .7098 & .1444 \\ 6167 & .7004\end{array}$

AW
.1219
.1235
.1257
.1330
.1340
.1411
.1571
1601
.1717
14112

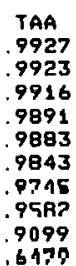

ZEN
n.,
20.0
30.0
48.2
50.0
60.0
70.0
75.0
80.0
85.0 DIRH
730.0409
871.3803
789.4391
571.0358
545.2446
393.9366
261.2079
155.8315
83.3321
25.5650

DIFSH

94. 9102

91.3142

1. 6248

91.3142

93. 9642

77.2467

69.8769

55.7656

39.5922

11.1038

1. 5273

1. 4082

1. 0月h

1.0470
8455

8155
.5567

.5567
.4135

4135
.2569

.0729

กTחT

1035.0359

966.090 .1

882.1616

65?. 1949

630.3058

471.7707

300.6456

212.0107

123.1812 


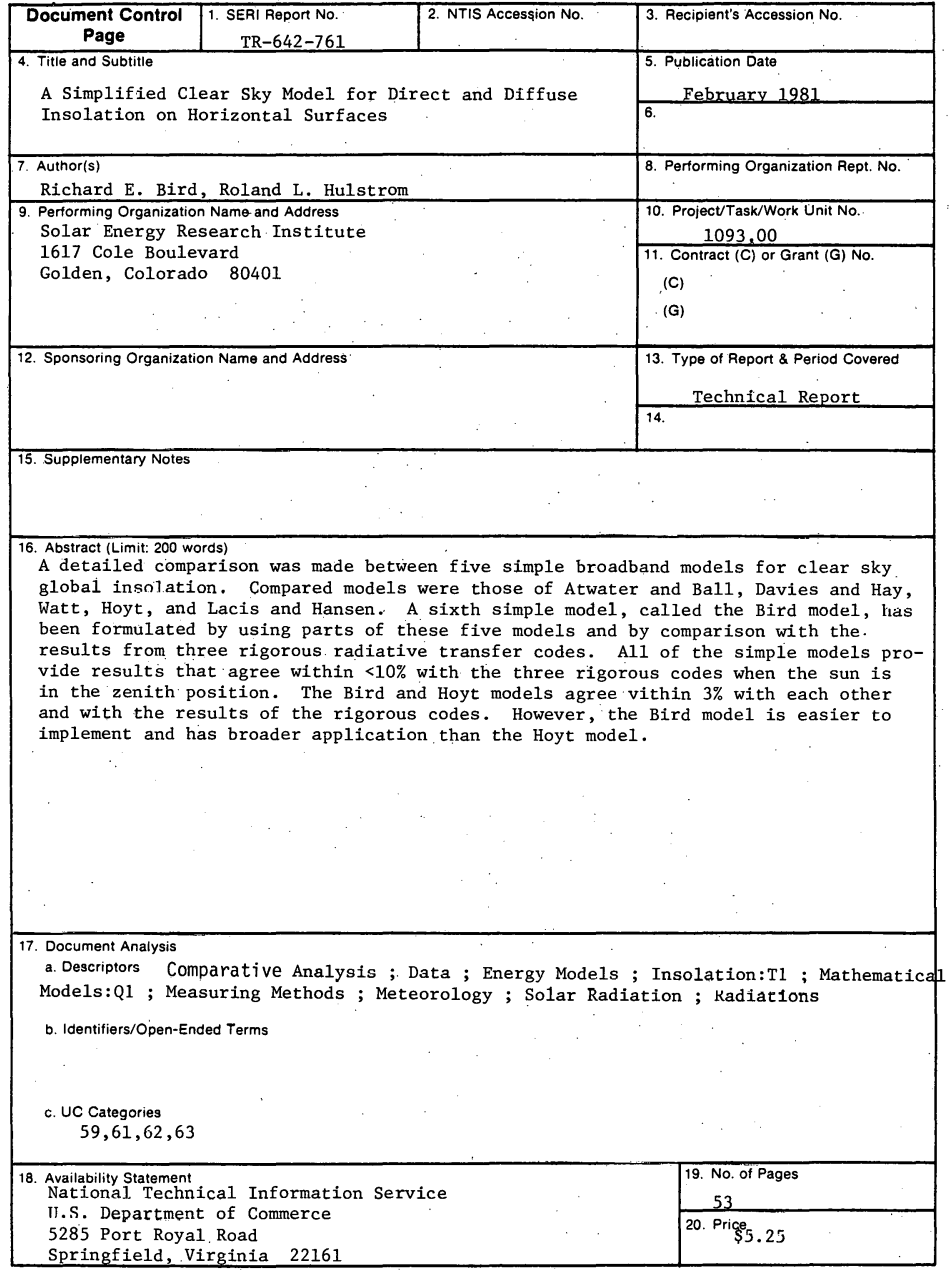

